\title{
Identificación de una tradición tecnológica cerámica con desgrasante óseo en el Neolítico peninsular. Estudio arqueométrico de materiales cerámicos de Madrid (5300-3400 cal AC)
}

\author{
Identification of a bone-tempered ceramic technological tradition in the Iberian Neolithic. \\ Archaeometric study of pottery from Madrid (5300-3400 cal BC)
}

\author{
Pedro Díaz-del-Río (*) \\ Susana Consuegra $(*)$ \\ Rosa Domínguez (**) \\ Asunción Martín-Bañón (***)
}

\author{
Lydia Vírseda $(* *)$ \\ Fernando Agua (****) \\ María-Ángeles Villegas $(* * * *)$ \\ Manuel García-Heras $(* * * *)$
}

\begin{abstract}
RESUMEN
La caracterización arqueométrica de un conjunto de materiales cerámicos procedentes de 6 yacimientos neolíticos de Madrid ha permitido identificar una nueva tradición tecnológica regional persistente en el tiempo, basada en la adición intencionada de hueso machacado como desgrasante en la mayoría de los recipientes cerámicos. Se trata del primer caso de la Península Ibérica en el que se documenta este tipo de desgrasante en cerámicas de estas cronologías con una continuidad temporal de entre el 5300/5200 hasta posiblemente el 3400 cal AC. Los materiales seleccionados se caracterizaron por técnicas mineralógicas y geoquímicas complementarias como lámina delgada, difracción de rayos $\mathrm{X}$ (DRX) convencional y de ángulo rasante, microscopía electrónica de barrido (MEB) y espectrometría de fluorescencia de rayos $\mathrm{X}$ (FRX). La adición de hueso produce un material cerámico ligero pero a su vez resistente, con ventajas tecnológicas para recipientes de almacenamiento $\mathrm{y} / \mathrm{o}$ transporte. Dichas ventajas quizá podrían vincularse a grupos con hábitos móviles o semisedentarios.
\end{abstract}

\footnotetext{
ABSTRACT

The archaeometric characterization of a set of potsherds from six Neolithic sites from the Madrid region has allowed the identification of a new and time-persisting regional technological tradition, based on the deliberated

(*) Grupo de Investigación Prehistoria Social y Económica. Instituto de Historia, CCHS, CSIC. C/ Albasanz 26-28. 28037 Madrid. Correos e.: pedro.diazdelrio@cchs.csic.es; susana.consuegra@cchs.csic.es

(**) Área Sociedad Cooperativa Arqueológica. C/ Aristóteles 10, bajo A. 28027 Madrid. Correo e.:

rmd@area-arqueologia.com
}

addition of crushed bone as temper in most pottery containers. This is the first known case in Iberia, and is outstanding because of its early chronologies and persistence in time: from 5300 to perhaps 3400 cal BC. Samples were characterized by complementary mineralogical and geochemical techniques such as thin-section, conventional and grazing angle X-ray diffraction (XRD), scanning electron microscopy (SEM) and X-ray fluorescence spectrometry $(X R F)$. The addition of bone temper created a light and resistant ceramic material, with technological advantages for both the storage and transportation. Such advantages might be linked to mobile or semi-sedentary groups.

Palabras clave: Prehistoria Reciente; Cerámica; Mediterráneo Occidental; Arqueometría; Tecnología; Desgrasante de hueso; Chamota.

Key words: Late Prehistory; Pottery; Western Mediterranean; Archaeometry; Technology; Bone-tempered pottery; Grog-tempered pottery.

\section{INTRODUCCIÓN}

El registro conocido del Neolítico Antiguo en la Península Ibérica presenta una elevada variabilidad en sus manifestaciones materiales. A la reconocida variación formal de las cerámicas car-

(***) C/ Gerardo Diego 14. 28806 Alcalá de Henares. Correo e.: asunción.martin@yahoo.es

$(* * * *)$ Grupo de Investigación Arqueometría y Conservación de Vidrios y Materiales Cerámicos. Instituto de Historia, CCHS, CSIC. C/ Albasanz 26-28. 28037 Madrid. Correos e.: fernando.agua@cchs.csic.es; mariangeles.villegas@cchs.csic.es; manuel.gheras@cchs.csic.es Recibido: 22-IX-2010; aceptado: 22-XI-2010. 
diales, se une la rápida multiplicación y diversificación de las evidencias neolíticas en la práctica totalidad de la península, tan sólo unos 100 años después de la aparición de las primeras especies domésticas, en torno al 5500 cal AC. Quizá el caso más destacable sea la regionalización que sugieren la pluralidad de prácticas agrícolas documentadas a escala peninsular (Zapata et al. 2005) o de tradiciones tecnológicas sugerida para las producciones epicardiales (Clop 2005).

Uno de los conjuntos materiales en los que debería mostrarse con mayor claridad esta aparente variabilidad regional es el de las producciones cerámicas, dado que, como sucede con todas las artesanías, el conocimiento especializado se transmite inevitablemente en el contexto de la práctica. Su aprendizaje requiere combinar un conocimiento teórico y un imprescindible saberhacer, por lo que una expansión rápida de la tecnología cerámica en el espacio y en el tiempo requeriría incrementar en unas pocas generaciones los individuos transmisores $\mathrm{y}$, en consecuencia, una previsible multiplicación de la variedad. Este fenómeno, que se observa con claridad a escala mediterránea (Fugazzola et al. 2002), parece también reflejarse a nivel peninsular.

Los todavía escasos yacimientos publicados no sugieren una variación sustancial en las formas o técnicas decorativas de las producciones del llamado Neolítico interior. Se puede asignar, con cierta probabilidad de éxito, un conjunto de cerámicas al Neolítico Antiguo en función de sus formas, decoraciones y del porcentaje de aparición de determinados tratamientos exteriores como la "almagra". Sin embargo, bajo esta aparente homogeneidad formal se insinúan tradiciones tecnológicas regionales, únicamente observables a partir de la caracterización mineralógica y geoquímica. El estudio arqueométrico de una muestra de materiales cerámicos recuperados en yacimientos neolíticos localizados en los valles madrileños del Jarama y el Manzanares permite elaborar una hipótesis en este sentido.

\section{LOCALIZACIÓN, CONTEXTO Y CRONOLOGÍA DE LOS MATERIALES CERÁMICOS ANALIZADOS}

La oportunidad de llevar a cabo un estudio arqueométrico de un conjunto de materiales cerámicos de 6 nuevos yacimientos neolíticos de Madrid resultó de una reunión organizada por el "Equipo Casa Montero" (CSIC) celebrada en ju- nio de 2007, en el Museo Arqueológico Regional de Madrid (MAR). Su objetivo era conocer de primera mano y comparar los conjuntos cerámicos neolíticos recuperados recientemente en Madrid, para construir una secuencia cerámica del Neolítico interior basada en criterios morfométricos, tecnológicos y petrográficos.

Todos los yacimientos muestreados se localizaron y excavaron como consecuencia del estudio arqueológico previo o seguimiento de obras públicas de distintas características. Se encuentran en el entorno inmediato de dos de los ríos principales de Madrid: el Jarama y el Manzanares (Fig. 1). Los
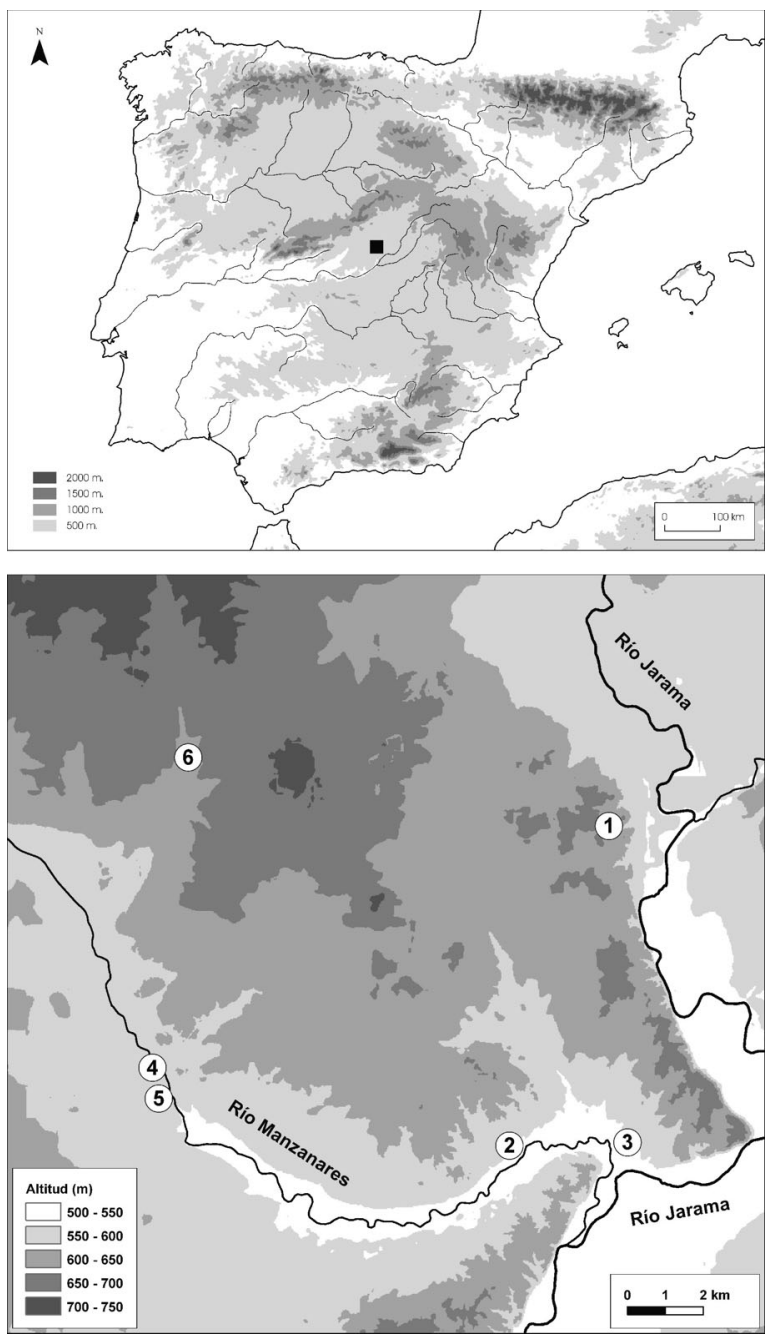

Fig. 1. Localización de los yacimientos neolíticos con materiales cerámicos analizados en la Península Ibérica y Madrid. 1. Casa Montero (Madrid); 2. El Congosto (Rivas-Vaciamadrid); 3. La Deseada (Rivas-Vaciamadrid); 4. Colector H05 (Madrid); 5. Pista de Motos (Madrid); 6. O’Donnell (Madrid). 
conjuntos son distintos en términos cuantitativos y cualitativos, 5 cuentan con dataciones absolutas, mientras que la tipología cerámica del único sin ellas, La Deseada (Díaz-del-Río y Consuegra 1999), puede adscribirse, razonablemente, al Neolítico Antiguo. En conjunto, son producciones cerámicas realizadas entre el 5300 y $3400 \mathrm{cal} \mathrm{AC}$.

A continuación se reseñan brevemente los yacimientos, desde el más antiguo al más moderno, y los correspondientes fragmentos cerámicos seleccionados para el estudio arqueométrico (Fig. 2). La tabla 1 describe los materiales analizados y la tabla 2 ofrece las dataciones absolutas disponibles.

La mina de sílex de Casa Montero (Madrid) se dio a conocer en 2004 (Consuegra et al. 2004) y es, en la actualidad, el yacimiento neolítico regional con mayor información contextual publicada. Se localiza en los escarpes de la margen derecha del río Jarama, a poco más de $1 \mathrm{~km}$ de su cauce. Las dataciones absolutas se han obtenido de fragmentos individuales de carbón, previamente identificados, recuperados en 12 pozos de extracción de sílex distribuidos por la práctica totalidad de las 3 ha detectadas de actividad minera prehistórica. El test de $\chi^{2}$ demuestra que 11 son estadísticamente idénticas, con un $65 \%$ de probabilidad de que todos los episodios mineros datados sucedieran entre el 5337 y el 5218 cal AC (Díaz-del-Río y Consuegra 2011). Dado que las muestras han sido seleccionadas sin atender a la posible "edad" de la madera, el resultado sugiere que o se seleccionaron siempre fragmentos de corteza, algo poco probable, o los restos datados pertenecían a maderas jóvenes, previsiblemente arbustos de coscoja y enebro. Dada la distribución de la muestra datada, los frecuentes remontajes entre grupos de pozos, la ausencia de superposición entre pozos y la homogeneidad tanto tipológica como tecnológica de los restos consideramos que el minado pudo durar un único siglo. En Casa
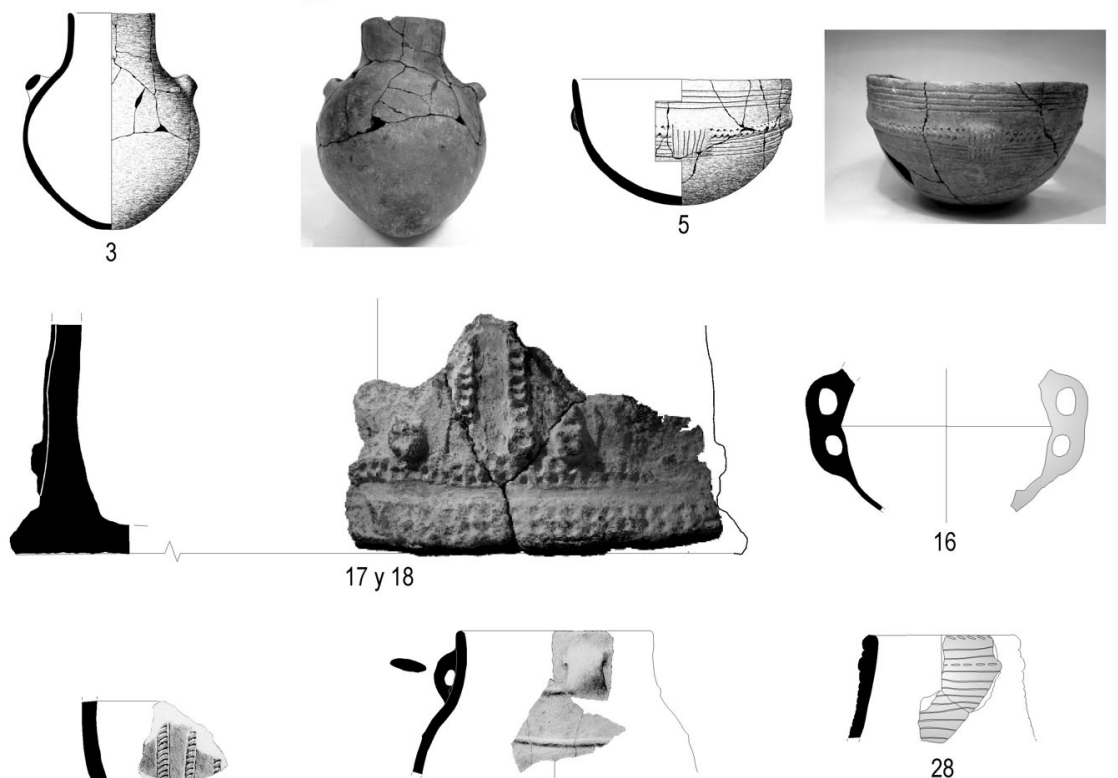

10

28
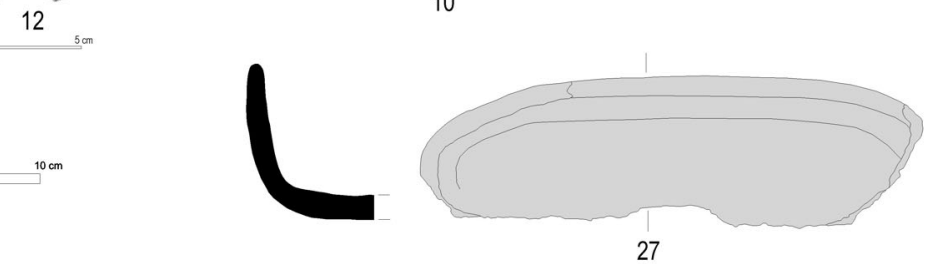

Fig. 2. Recipientes madrileños del Neolítico analizados. Muestras 3 y 5 Casa Montero (Madrid). Muestra 10 La Deseada (Rivas-Vaciamadrid). Muestras 12, 16, 17 y 18 El Congosto (Rivas-Vaciamadrid). Muestras 27 y 28 Pista de Motos (Madrid). 


\begin{tabular}{|c|c|c|c|c|c|c|c|c|c|c|}
\hline \multirow{2}{*}{ Muestra } & \multirow{2}{*}{ Yacimiento } & \multirow{2}{*}{ Identificación } & \multicolumn{6}{|c|}{$\begin{array}{l}\mathrm{N}^{\circ} \text { de inclusiones } \\
\text { (índice medio de esfericidad*, u.a.) }\end{array}$} & \multirow[t]{2}{*}{ Crono. } & \multirow[t]{2}{*}{ Descripción } \\
\hline & & & Hueso & Chamota & Carbón & 1 & 2 & 3 & & \\
\hline 1 & Casa Montero & UE 581 & & & & & & & EB & $\begin{array}{l}\text { Galbo con cordones aplica- } \\
\text { dos impresos }\end{array}$ \\
\hline 2 & Casa Montero & UE 233 & $63(0,54)$ & & & & $\mathrm{x}$ & & NA & Galbo bruñido \\
\hline 3 & Casa Montero & UE 16225 & $167(0,64)$ & & & & & $\mathrm{x}$ & NA & $\begin{array}{l}\text { Botella de dos asas con al- } \\
\text { magra }\end{array}$ \\
\hline 4 & Casa Montero & UE 9480 & $104(0,64)$ & $5(0,70)$ & & & & & NA & Forma 2 , incisiones, cordón \\
\hline 5 & Casa Montero & UE 16225 & $66(0,68)$ & & & & & $\mathrm{x}$ & NA & $\begin{array}{l}\text { Cuenco acanalado, cordón } \\
\text { impreso, almagra }\end{array}$ \\
\hline 6 & Casa Montero & UE 386 & $84(0,65)$ & & $3(0,70)$ & & & $\mathrm{x}$ & NA & Galbo bruñido almagra \\
\hline 7 & Casa Montero & UE 16641 & $125(0,60)$ & $3(0,77)$ & & & & $\mathrm{x}$ & NA & Galbo almagra \\
\hline 8 & La Deseada & UE 4501 & & & & $\mathrm{x}$ & $\mathrm{x}$ & & NA & Gran recipiente no decorado \\
\hline 9 & La Deseada & UE 8601 & $34(0,64)$ & & & & & & NA & Fragmento base cóncava \\
\hline 10 & La Deseada & $98 / 123-37 / 8601-1$ & & $23(0,69)$ & & & $\mathrm{x}$ & $\mathrm{x}$ & NA & Galbo almagra \\
\hline 11 & La Deseada & $98 / 123-37 / 8101-4$ & $7(0,70)$ & $5(0,79)$ & & & & $\mathrm{x}$ & NA & Incisa, impresa, almagra \\
\hline 12 & El Congosto & $04 / 6 / 1811 / 24$ & $20(0,62)$ & & $3(0,76)$ & & & & NA & Galbo inciso e impreso \\
\hline 13 & El Congosto & $04 / 06 / 1811 / 16$ & $55(0,62)$ & & & & & & NA & $\begin{array}{l}\text { Cordón con impresiones de } \\
\text { punzón }\end{array}$ \\
\hline 14 & El Congosto & $04 / 6 / 2246 / 2$ & $33(0,68)$ & & & & $\mathrm{x}$ & & NA & $\begin{array}{l}\text { Borde con dos cordones ho- } \\
\text { rizontales paralelos, supe- } \\
\text { rior ungulado }\end{array}$ \\
\hline 15 & El Congosto & $04 / 6 / 5451 / 5$ & $164(0,56)$ & & & & & & NA & Galbo bruñido \\
\hline 16 & El Congosto & $04 / 6 / 5049 / 1$ & $31(0,63)$ & & & & & $\mathrm{x}$ & NA & $\begin{array}{l}\text { Botella con doble asa verti- } \\
\text { cal con almagra }\end{array}$ \\
\hline 17 & El Congosto & $04 / 6 / 4721 / 9$ & & & & $\mathrm{x}$ & $\mathrm{x}$ & & NA & $\begin{array}{l}\text { Gran recipiente con cordo- } \\
\text { nes impresos }\end{array}$ \\
\hline 18 & El Congosto & $04 / 6 / 5049 / 5$ & & & & $\mathrm{x}$ & & & NA & $\begin{array}{l}\text { Gran recipiente con cordo- } \\
\text { nes impresos }\end{array}$ \\
\hline 19 & Colector H05 & UE 4041 & $93(0,62)$ & & & & & & NM & Galbo impreso \\
\hline 20 & Colector H05 & UE 4041 & $80(0,59)$ & & & & & & NM & Galbo \\
\hline 21 & Colector H05 & UE 4041 & & & & $\mathrm{x}$ & & & NM & Gran recipiente no decorado \\
\hline 22 & Colector H05 & UE 4001 & $65(0,63)$ & & & & & & NM & Galbo liso \\
\hline 23 & Colector $\mathrm{H} 05$ & UE 4001 & $93(0,62)$ & & & & & & NM & Galbo liso rodado \\
\hline 24 & O’Donnell & 04/57/H-10 & & & & & & & NF & Galbo liso \\
\hline 25 & O’Donnell & 04/57/H-11 & & & & & $\mathrm{x}$ & & NF & Galbo liso \\
\hline 26 & Pista de Motos & UE 2491 & $85(0,65)$ & & & & $\mathrm{x}$ & & NF & Borde galbo inciso, impreso \\
\hline 27 & Pista de Motos & $06 / 07 / 2301 \mathrm{~s} / \mathrm{n}$ & & & & & & & NF & Fuente sub-rectangular \\
\hline 28 & Pista de Motos & 06/07/2301/1 & & & $35(0,64)$ & & $\mathrm{x}$ & & NF & $\begin{array}{l}\text { Borde galbo inciso con im- } \\
\text { presiones en labio }\end{array}$ \\
\hline 29 & Casa Montero & & & & & & & & Terciario & Sedimento arcilloso \\
\hline
\end{tabular}

Tab. 1. Descripción de los materiales cerámicos madrileños analizados y número de inclusiones estimado en la observación de las láminas delgadas. 1 = Fibra Vegetal, 2 = calcita secundaria, $3=$ Almagra, $\mathrm{X}=$ Presencia, * Índice de esfericidad de Riley (1953). EB = Edad del Bronce. $\mathrm{NA}=$ Neolítico Antiguo. $\mathrm{NM}=$ Neolítico Medio. $\mathrm{NF}=$ Neolítico Final. U.a. $=$ Unidades arbitrarias. U.e. $=$ Unidad estratigráfica.

Montero se ha recuperado uno de los mejores conjuntos cerámicos del Neolítico Antiguo del interior peninsular, tanto en términos cuantitativos como cualitativos. Se seleccionaron 7 fragmentos cerámicos: 6 proceden de 5 pozos neolíticos y 1 de un hoyo fechado en la Edad del Bronce. Este último fragmento se seleccionó para determinar posibles diferencias tecnológicas diacrónicas.

La Deseada (Rivas-Vaciamadrid, Madrid) se localizaba en los escarpes yesíferos del valle del Jarama, a $50 \mathrm{~m}$ de su cauce, prácticamente en su confluencia con el río Manzanares (Díaz-del-Río y Consuegra 1999). En el yacimiento se documentó la única evidencia arquitectónica clara del Neolítico antiguo regional publicada hasta la actualidad, además de 4 estructuras, de las cuales una puede interpretarse como silo subterráneo. Como recordaremos, es el único sin dataciones absolutas, pero sus escasos materiales cerámicos son distintivos del Neolítico Antiguo. Se seleccionaron 4 fragmentos cerámicos: 3 recuperados en los hoyos y 1 en la cabaña. 


\begin{tabular}{|c|l|l|l|l|l|c|c|}
\hline $\mathbf{N}^{\mathbf{2}}$ & \multicolumn{1}{|c|}{ Laboratorio } & \multicolumn{1}{|c|}{ Yacimiento } & \multicolumn{1}{|c|}{ T.M. } & \multicolumn{1}{c|}{ Id. } & Material & Fecha BP & Cal AC 2 $\sigma$ \\
\hline 1 & Beta-206512 & Casa Montero & Madrid & 2384 & Quercus ilex/cocc. & $6400 \pm 40$ & $5471-5318$ \\
2 & Beta-206513 & Casa Montero & Madrid & 2701 & Quercus ilex/cocc. & $6270 \pm 40$ & $5324-5077$ \\
3 & Beta-232884 & Casa Montero & Madrid & 7244 & Quercus ilex/cocc. & $6360 \pm 40$ & $5469-5227$ \\
4 & Beta-232885 & Casa Montero & Madrid & 7564 & Quercus ilex/cocc. & $6280 \pm 40$ & $5359-5080$ \\
5 & Beta-232886 & Casa Montero & Madrid & 7490 & Quercus ilex/cocc. & $6350 \pm 40$ & $5466-5224$ \\
6 & Beta-232887 & Casa Montero & Madrid & 7967 & Juniperus com. & $6290 \pm 40$ & $5367-5085$ \\
7 & Beta-232888 & Casa Montero & Madrid & 8147 & Quercus ilex/cocc. & $6240 \pm 40$ & $5310-5066$ \\
8 & Beta-232889 & Casa Montero & Madrid & 15849 & Juniperus com. & $6290 \pm 40$ & $5367-5085$ \\
9 & Beta-232890 & Casa Montero & Madrid & 16309 & Quercus ilex/cocc. & $6500 \pm 40$ & $5534-5370$ \\
10 & Beta-232891 & Casa Montero & Madrid & 8615 & Quercus ilex/cocc. & $6320 \pm 40$ & $5460-5214$ \\
11 & Beta-232892 & Casa Montero & Madrid & 9332 & Quercus ilex/cocc. & $6270 \pm 40$ & $5324-5077$ \\
12 & Beta-232893 & Casa Montero & Madrid & 9630 & Quercus ilex/cocc. & $6330 \pm 40$ & $5463-5217$ \\
13 & KIA-27582 & El Congosto & Rivas-Vac. & $2242-3$ & Hueso humano & $6015 \pm 50$ & $5041-4788$ \\
14 & Beta-206546 & O'Donnell & Madrid & Coluvión inf. & Carbón & $5910 \pm 40$ & $4898-4696$ \\
15 & MAD- 4310 (TL) & O'Donnell & Madrid & Coluvión sup. & Cerámica & $5041 \pm 414$ & - \\
16 & DSH 275 & Colector H05 & Villaverde & 4040 & Fauna n/d & $5705 \pm 30$ & $4667-4459$ \\
17 & DSH246 & Pista de Motos & Villaverde & 2300 & Fauna n/d & $4639 \pm 18$ & $3499-3364$ \\
\hline
\end{tabular}

Tab. 2. Dataciones absolutas de los yacimientos neolíticos madrileños estudiados. n/d No determinado.

El yacimiento de El Congosto (Rivas-Vaciamadrid, Madrid) se situaba sobre una suave loma a $400 \mathrm{~m}$ del cauce del río Manzanares, a algo menos de $4 \mathrm{~km}$ de su confluencia con el río Jarama. Durante la intervención, desarrollada en 2004 (Martín Bañón 2007), se abrió un total de 1,39 ha, donde se localizaron 416 fosas prehistóricas. Sólo 16 contenían materiales asignables tipológicamente al Neolítico Antiguo. Las pocas estructuras de esta cronología así como el remontaje de fragmentos cerámicos entre algunas sugieren una única ocupación, quizá no muy prolongada en el tiempo. En general, son fosas de planta circular de $1 \mathrm{~m}$ de diámetro aproximadamente y escasa profundidad, denominadas frecuentemente "cubetas". En dos casos pudieron servir como silos subterráneos por la morfología de los perfiles. En uno de estos silos se halló el enterramiento doble de un infante y un adulto, previsiblemente en posición primaria dada la presencia de la práctica totalidad del esqueleto del segundo. Un hueso del adulto se fechó en 5041-4788 cal AC (Tab. 2). De los 589 fragmentos cerámicos recuperados, se seleccionaron 7 procedentes de 5 estructuras diferentes.

El yacimiento conocido como Colector $\mathrm{H} 05$ (Villaverde, Madrid) se sitúa en la margen izquierda del río Manzanares, a $20 \mathrm{~m}$ de su cauce actual. En una extensión reducida de $140 \mathrm{~m}^{2}$ se documentaron 14 estructuras en planta. Se excavaron 8 , de las cuales 6 ya estaban seccionadas por la zanja que albergaría el colector. Cuatro aportaron materiales asignables al Neolítico. Un fragmento de fauna indeterminada recuperado en una de estas estructuras se fechó en 4667-4459 cal AC (Tab. 2). De los 168 fragmentos cerámicos recuperados se seleccionaron 5 procedentes de la estructura datada.

El yacimiento de Pista de Motos (Villaverde, Madrid) se situaba en terraza, en la margen derecha del río Manzanares, a $170 \mathrm{~m}$ de su cauce actual (Domínguez y Vírseda 2009). Se excavó 0,6 ha, documentándose 350 estructuras. Sólo dos de ellas se asignaron al Neolítico. Son de tipo silo y en su interior se recuperaron 93 fragmentos cerámicos. Corresponden a formas predominantemente globulares y semiesféricas, con algunas decoraciones impresas y boquiques, así como otras claramente calcolíticas, como una fuente sub-rectangular. Un fragmento de fauna indeterminada de una de las estructuras neolíticas dató la aparentemente breve ocupación en 3499-3364 cal AC (Tab. 2). Es una de las pocas fechas absolutas existentes en contextos no funerarios de la Meseta de estas cronologías. De los 3 fragmentos seleccionados para su análisis, 2 pertenecen a la estructura datada (ue 2301).

El depósito coluvional de O'Donnell (Madrid) se localizó durante las obras de seguimiento de la remodelación de la circunvalación interior de Madrid (M-30). Los materiales procedían, probablemente, del desmantelamiento de un asentamiento ubicado en una de las terrazas intermedias de la margen derecha del arroyo Abroñigal, afluente del río Manzanares. La muestra de carbón que se dató, con una cronología de 4898-4696 cal AC (Tab. 2), procede de un depó- 
sito coluvional situado directamente bajo el estrato que ofreció materiales arqueológicos y, en consecuencia, debe considerarse terminus ante quem. En total se recuperaron 23 pequeños fragmentos cerámicos, de los que únicamente uno es un borde digitado de una posible forma globular. Entre los galbos destaca una posible aguada-engobe. De este yacimiento se seleccionaron 2 fragmentos. Junto a los materiales cerámicos se recuperaron también más de quinientos fragmentos de industria lítica compuesta por varios núcleos laminares y un importante número de fragmentos de lámina, muchos de ellos calentados. El conjunto podría corresponder a un único momento crono-cultural. La datación por termoluminiscencia (TL) de uno de los fragmentos cerámicos (5041 \pm 414 BP, Tab. 2) indica que la cronología de este coluvión debe situarse entre la segunda mitad del IV y primera del III milenio AC. Previsiblemente es el conjunto más reciente de los analizados.

\section{MATERIALES Y TÉCNICAS DE ANÁLISIS}

\subsection{Muestras seleccionadas}

Se analizaron 29 muestras: 28 fragmentos cerámicos y 1 muestra de sedimento arcilloso (Tab. 1). Los primeros proceden de los seis yacimientos reseñados: Casa Montero (7 frags.), La Deseada (4 frags.), El Congosto (7 frags.), Colector H05 (5 frags.), O’Donnell (2 frags.) y Pista de Motos (3 frags.). La selección se realizó a partir de sus características texturales externas y de su tipología. Seis de los fragmentos seleccionados presentan "almagra", en general muy deteriorada, en sus superficies externas: Casa Montero (4 frags.), La Deseada (1 frag.) y El Congosto (1 frag.). Cuatro de las muestras pertenecen a recipientes de grandes dimensiones procedentes de La Deseada (1 frag.), El Congosto (2 frags.) y Colector H05 (1 frag.). El sedimento arcilloso procede de un estrato terciario muestreado durante la excavación de Casa Montero.

\subsection{Técnicas de análisis}

Se utilizaron las siguientes técnicas complementarias de caracterización mineralógica y geo- química: análisis petrográfico mediante lámina delgada, difracción de rayos X (DRX) convencional y de ángulo rasante, microscopía electrónica de barrido (MEB) con microanálisis de dispersión de energías de rayos X (EDS) y espectrometría de fluorescencia de rayos X (FRX). Las características macroscópicas de todas las muestras se observaron, previamente, sobre fracturas frescas y secciones pulidas.

Las láminas delgadas se prepararon a partir de una sección obtenida con un disco de corte de diamante y perpendicular al borde de los fragmentos cerámicos. Su observación petrográfica se llevó a cabo con un microscopio óptico de luz transmitida y dispositivo de polarización Kyowa Bio-Pol 2. Las micrografías se obtuvieron con una cámara digital Leica DFC480.

Los análisis mediante DRX del interior de los fragmentos cerámicos y del sedimento arcilloso se realizaron con el método convencional de polvo cristalino con un difractómetro PANalytical X'Pert MPD, utilizando la radiación $\mathrm{K} \alpha$ del cobre $(1,54060 \AA)$ y condiciones de trabajo de 45 $\mathrm{kV}$ y $40 \mathrm{~mA}$. Los difractogramas se registraron entre $2 \theta=5-60^{\circ}$. Los análisis por DRX con ángulo rasante se efectuaron sobre la superficie de los fragmentos con "almagra". Se utilizó un difractómetro PANalytical X'Pert PRO MPD y radiación $\mathrm{K} \alpha$ del cobre (1,54060 Å), con espejo parabólico como atenuador del haz directo, rendija de divergencia de $1 / 16^{\circ}$ y máscara de $10 \mathrm{~mm}$. Los difractogramas se registraron entre $2 \theta=10-60^{\circ}$.

Las observaciones microestructurales se llevaron a cabo mediante MEB sobre fractura fresca. Se utilizó un equipo Hitachi S-3400-N (CCHS-CSIC, Madrid) con tensión de aceleración de $15 \mathrm{kV}$. Las fracturas se recubrieron con una fina capa de oro-paladio, depositada con un evaporador Polaron SC7620, para favorecer la conducción. Las observaciones de los fragmentos con "almagra" se realizaron sobre sección pulida embutida en resina y recubierta con una fina capa de carbono. Los microanálisis por EDS se llevaron a cabo con un espectrómetro Bruker AXS acoplado al microscopio electrónico mencionado.

La composición química en masa de todas las muestras seleccionadas se determinó semicuantitativamente con un espectrómetro de FRX de dispersión de longitudes de onda PANalytical Axios, equipado con tubo de rodio. Las muestras se prepararon prensadas en pastillas de ácido bórico con 
n-butilmetacrilato y acetona (10:90\% en peso) como agentes ligantes. Se determinaron las concentraciones de los 12 óxidos siguientes: $\mathrm{Na}_{2} \mathrm{O}$, $\mathrm{MgO}, \mathrm{Al}_{2} \mathrm{O}_{3}, \mathrm{SiO}_{2}, \mathrm{P}_{2} \mathrm{O}_{5}, \mathrm{~K}_{2} \mathrm{O}, \mathrm{CaO}, \mathrm{TiO}_{2}, \mathrm{MnO}$, $\mathrm{Fe}_{2} \mathrm{O}_{3}$, SrO y $\mathrm{BaO}$. Se eligieron estos 12 óxidos por presentar niveles de exactitud y precisión aceptables para todas las muestras analizadas. Las muestras de polvo para los análisis mediante DRX y FRX se obtuvieron por molienda del fragmento cerámico con un mortero y mazo de ágata. Se eliminó la superficie más externa de los fragmentos para evitar posibles contaminaciones.

Finalmente, con el fin de aislar y estimar la validez estadística de posibles grupos de fragmentos cerámicos que mostraran un perfil químico similar, los datos de composición química obtenidos por FRX se emplearon dos técnicas estadísticas multivariantes con el paquete estadístico Systat v. 10.2 (SPSS Inc., Chicago): análisis de componentes principales y análisis canónico discriminante, el cual incluyó el cálculo de distancias de Mahalanobis (Baxter 1994). Las concentraciones de los distintos óxidos se transformaron en valores logarítmicos para compensar las diferencias de magnitud entre los óxidos mayoritarios y minoritarios en el cálculo de los coeficientes de similaridad (Bishop y Neff 1989).

\section{RESULTADOS Y DISCUSIÓN}

\subsection{Observación macroscópica}

La observación macroscópica de las muestras determinó una fábrica mayoritaria y bastante homogénea en los fragmentos cerámicos. Las matrices arcillosas presentaron coloraciones heterogéneas, con predomino de áreas grisáceas y/o negruzcas y, en menor proporción, zonas marrones y/o rojizas. Un número importante de fragmentos mostraron corazón negro, así como una elevada macro-porosidad. En esta fábrica se observaron abundantes inclusiones distribuidas por toda la matriz arcillosa, con tamaños de hasta $3 \mathrm{~mm}$. Sólo en las muestras 8, 17, 18 y 2, procedentes de grandes recipientes se determinó una fábrica con menor densidad de inclusiones $\mathrm{y}$, además, de menor tamaño (hasta $0,7 \mathrm{~mm}$ ). En la superficie externa de la muestra 17 se identificó una zona con evidencias de vitrificación de unos $3 \mathrm{~mm}$ de espesor.

\subsection{Observación petrográfica}

La observación petrográfica de las láminas delgadas no reveló, en su conjunto, diferencias mineralógicas importantes entre los fragmentos cerámicos. En la fábrica que mostró un mayor número y tamaño de inclusiones se determinaron matrices birrefringentes sin signos de vitrificación, con colores ocres y marrones y abundantes cambios de tonalidad. Esta heterogeneidad indica un escaso control de las atmósferas de cocción. Los poros presentaron una morfología alargada y una orientación paralela a las superficies de los fragmentos. En esta fábrica las inclusiones aparecieron diseminadas por toda la matriz, con una gradación de tamaños desde unos pocos micrómetros hasta aproximadamente $2,5 \mathrm{~mm}$. La mineralogía de las inclusiones está compuesta mayoritariamente por cuarzo, en general monocristalino (Fig. 3a-b); feldespatos, en los términos sódico (plagioclasa) y potásico (microclina), con predominio de la plagioclasa; y mica, generalmente de la variedad biotita. En menor medida y sólo en algunas muestras se identificaron nódulos opacos de óxido de hierro. El tamaño máximo de las inclusiones de cuarzo no sobrepasó los 2,5 mm en la mayoría de las muestras, aunque en la muestra 10 algunas inclusiones alcanzaron los 3,0 mm (Fig. 3c). Los feldespatos mostraron un tamaño máximo menor, que no sobrepasó los $0,8 \mathrm{~mm}$ en las plagioclasas y los 1,3 $\mathrm{mm}$ en las microclinas. Las inclusiones de cuarzo y feldespatos tenían formas redondeadas y sub-redondeadas (índice medio de esfericidad 0,75), lo que podría indicar que ya formaban parte del sedimento utilizado para fabricar la cerámica y que descarta su adición intencionada a la matriz arcillosa como desgrasante o material no plástico. El tamaño máximo de la mica, con hábito acicular, alcanzó los 0,6-0,8 mm, mientras que el tamaño de los nódulos opacos de óxido de hierro, con formas redondeadas, no superó los 0,6 mm. En las muestras 1, 2, y 6 procedentes de Casa Montero se identificaron fragmentos de roca granítica, a veces de hasta 2,2 mm de tamaño. Asimismo, en la muestra 10 con "almagra" procedente de La Deseada, se determinaron inclusiones de calcita micrítica primaria de forma redondeada y tamaño no superior a $0,8 \mathrm{~mm}$ (Fig. 3c), pero no feldespatos.

Tanto las matrices como la composición mineralógica de las inclusiones presentaron características muy similares en la fábrica con menor 

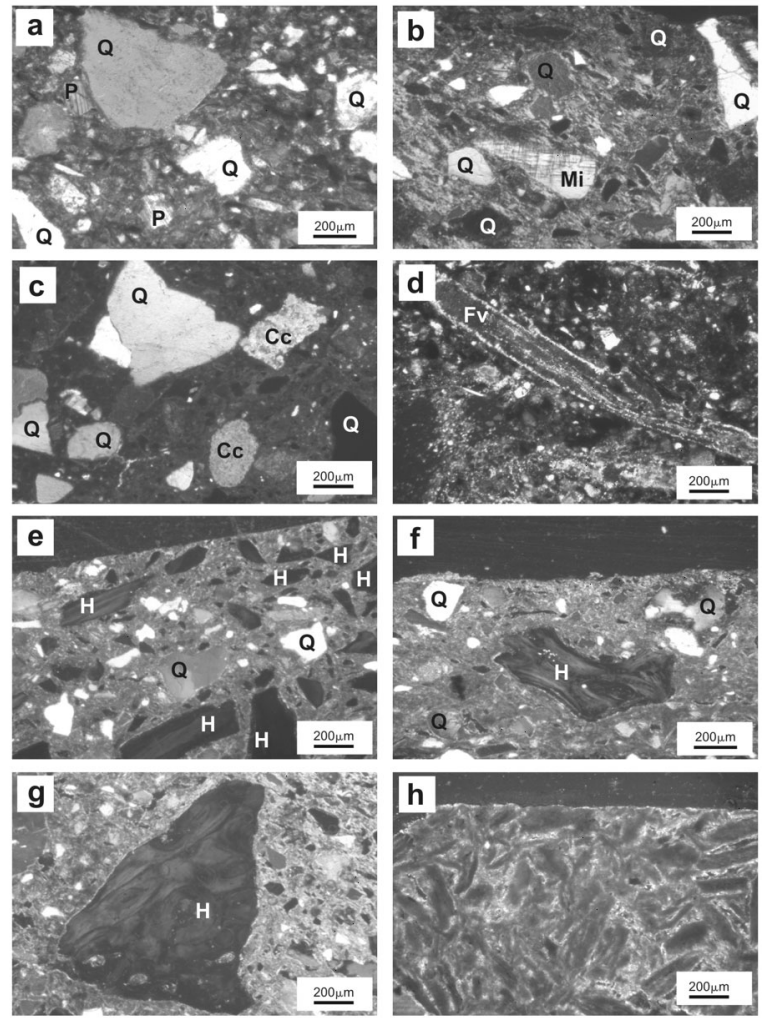

Fig. 3. Micrografías de lámina delgada. Nícoles cruzados. a) Muestra 27. b) Muestra 19. c) Muestra 10. d) Muestra 17. e) Muestra 15. f) Muestra 16. g) Muestra 13. h) Muestra 29. Cc. Calcita. Fv. Huella de fibra vegetal. H. Hueso. Mi. Microclina (feldespato potásico). P. Plagioclasa (feldespato sódico). Q. Cuarzo. Procedencia y cronología de las muestras en tabla 1.

densidad y tamaño de grano identificada en la observación macroscópica y asociada a grandes recipientes. Las matrices birrefringentes tampoco presentaron evidencias de vitrificación, aunque la matriz mostró un componente más arenoso y más calcáreo en las muestras 17 y 18 procedentes de El Congosto. En las muestras 8, 17, 18 y 21 se reconocieron huellas estrechas y alargadas, cuya morfología podría relacionarse con restos de fibras vegetales (Fig. 3d). El tamaño máximo del cuarzo, los feldespatos y la mica no superó los 0,5-0,7 mm, mientras que los nódulos opacos de óxido de hierro no superaron $0,3 \mathrm{~mm}$. Las micas mostraron también hábito acicular y el resto de las inclusiones, formas redondeadas y sub-redondeadas.

Los fragmentos de granito reconocidos en algunas muestras de Casa Montero, junto a cristales de cuarzo, de plagioclasa y/o microclina, por lo demás similares a los hallados en las inclusiones individuales de la mayoría de las muestras analizadas, indican que los sedimentos arcillosos empleados en la elaboración de esta cerámica podrían proceder de la alteración y meteorización de un área predominantemente granítica. No obstante, la ausencia de feldespatos y la presencia de calcita micrítica primaria en la muestra 10 ("almagra" de La Deseada) son características que la hacen geológicamente incompatible con un área granítica, lo cual podría indicar que este fragmento cerámico tiene un origen foráneo. Excepto en este caso, no es posible establecer mayores diferenciaciones, ni por yacimiento ni por cronología, a partir de la composición mineralógica determinada mediante observación petrográfica.

\subsubsection{Identificación de hueso y otro tipo de inclusiones}

Junto a las inclusiones minerales, se reconocieron inclusiones muy numerosas de hueso (Fig. 3e-f-g) y, en mucha menor proporción, fragmentos de chamota (Fig. 4a), carbón (Fig. 4b-c) y calcita secundaria o de aporte externo (Fig. 4d).

Las inclusiones de hueso aparecieron en $18 \mathrm{de}$ las muestras (Tab. 1). Excepto los grandes recipientes (muestras 8, 17, 18 y 21), la muestra 1 de Casa Montero (perteneciente a la Edad del Bronce), la 10 de La Deseada, los dos fragmentos cerámicos de O'Donnell y dos de Pista de Motos, todos los fragmentos analizados tenían inclusio-
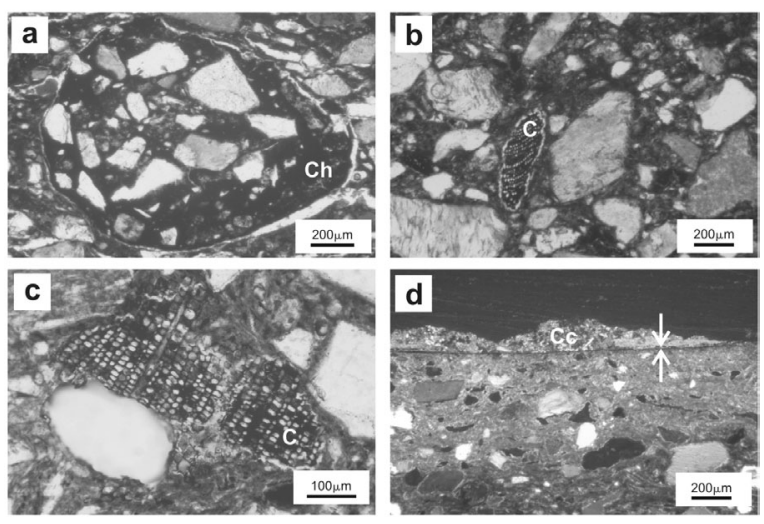

Fig. 4. Micrografías de lámina delgada. Luz plana (a-c). Nícoles cruzados (b-d). a) Muestra 7. b-c) Muestra 28. d) Muestra 16. Las flechas indican la situación de la capa de "almagra". C. Carbón. Cc. Calcita. Ch. Chamota. Procedencia y cronología de las muestras en tabla 1. 
nes de hueso o, lo que es lo mismo, sólo faltaban en las cerámicas de O’Donnell (1). El número de estas inclusiones se estimó en cada lámina delgada mediante conteo directo y abarcó el intervalo comprendido entre siete inclusiones de hueso de la muestra 11 (La Deseada), hasta 167 inclusiones contadas en la muestra 3 (Casa Montero). Los tamaños máximos se situaron entre $0,4 \mathrm{~mm}$ de la muestra 12 (El Congosto) y 1,5 mm de la muestra 13 (El Congosto). La presencia de morfologías angulosas, con un índice medio de esfericidad bajo en comparación con las inclusiones de cuarzo y feldespatos $(0,63$ frente a 0,75$)$ (Tab. 1 ; Fig. 3e-f-g), así como el elevado número de estas inclusiones, indican su posible adición intencionada al sedimento arcilloso. Además, la identificación de ciertas características histológicas como osteocitos circulares (Fig. 3g) demuestra que estas inclusiones consisten en fragmentos de hueso machacado deliberadamente para añadirse como desgrasante. Los datos aportados por el sedimento arcilloso procedente de Casa Montero (muestra 29) (2) también refuerzan el carácter intencional. Aparte de mostrar una matriz muy diferente a la de la cerámica, con cristales arcillosos escasamente sinterizados a pesar de su cocción a $750{ }^{\circ} \mathrm{C}$, este sedimento carecía de inclusiones de hueso como las de las muestras de los fragmentos cerámicos (Fig. 3h). Estas características, junto a la ausencia de otras inclusiones minerales de tamaño variable, sugieren que no se utilizó un sedimento como el muestreado en la elaboración de los materiales cerámicos analizados.

(1) Una documentación más extensa sobre la observación petrográfica de los fragmentos cerámicos procedentes de Casa Montero puede consultarse en García-Heras, M.; Agua, F. y Villegas, M. A. en prensa: "Estudio arqueométrico de materiales cerámicos del yacimiento de Casa Montero, Madrid". En S. Consuegra y P. Díaz-del-Río (eds.): Casa Montero. Una mina de sílex del Neolítico Antiguo. CSIC. Madrid.

(2) Este sedimento, procedente de la excavación de un estrato terciario de Casa Montero, se analizó para comprobar su uso como materia prima en la elaboración de los materiales cerámicos. Para simular su tecnología, el sedimento se procesó en el laboratorio del siguiente modo. Una vez secado a temperatura ambiente, se le añadió agua y se modeló en pequeñas probetas rectangulares, que posteriormente se secaron en estufa a $80^{\circ} \mathrm{C}$ durante $120 \mathrm{~min}$. Después, se cocieron en un horno eléctrico en atmósfera oxidante a $750{ }^{\circ} \mathrm{C}$. La cocción se realizó con un temple de $120 \mathrm{~min}$., durante el cual la temperatura se elevó lentamente hasta alcanzar $300^{\circ} \mathrm{C}$. Más tarde, en un segundo paso, la temperatura se elevó hasta $750{ }^{\circ} \mathrm{C}$ en $80 \mathrm{~min}$. La máxima temperatura sólo se estabilizó durante $15 \mathrm{~min}$. Por último, el horno se mantuvo cerrado para que tuviera lugar un enfriamiento lento y prolongado.
La chamota, fragmentos de cerámica machacada añadidos como desgrasante no plástico al sedimento (Rice 1987: 75), también se considera intencional. Se identificaron fragmentos de entre 0,6 y 1,6 mm de tamaño máximo en 4 muestras: Casa Montero n. ${ }^{\circ} 4$ y 7 , y La Deseada n. ${ }^{\circ} 10$ y 11 (Tab. 1). En tres combina con el desgrasante óseo. La discontinuidad con respecto a la matriz circundante es clara (Fig. 4a): al ser materiales distintos tienen coeficientes de dilatación diferentes.

Al haber inclusiones de hueso y chamota en fragmentos cerámicos con y sin "almagra", no es posible asociar su presencia o ausencia con este tratamiento de la superficie. En cambio, sólo se detectó chamota en muestras de los yacimientos considerados más antiguos: Casa Montero y La Deseada (3). Además, en la muestra 10, incompatible con un área granítica, se contabilizaron el máximo de inclusiones de chamota (23 en total).

Solamente se hallaron fragmentos de carbón o restos de materia orgánica carbonizada en las muestras 6, 12 y 28 (Tab. 1). Dos tenían un número muy reducido, mientras en la 28 , procedente de Pista de Motos, se contabilizaron hasta 35 inclusiones. Posiblemente, algunas puedan asociarse con madera carbonizada debido a las alineaciones de su estructura celular (Fig. 4b-c). En todo caso, ninguna evidencia excluye que estuvieran ya en el sedimento utilizado en la elaboración de la cerámica. Por último, también se identificó calcita micrítica secundaria o de aporte externo en 9 de las muestras analizadas. En general, se halló depositada en las superficies externas de los fragmentos. Esto ha contribuido, en algunos casos, a una mejor conservación de la capa de "almagra" (Fig. 4d).

\subsection{Análisis mediante DRX convencional}

Las fases mineralógicas determinadas mediante DRX confirmaron los datos petrográficos. Se identificó igualmente una mineralogía homogénea caracterizada por cuarzo, plagioclasa y microclina como fases principales, que pueden asociarse al componente granítico representado por las inclusiones de mayor tamaño. Asimismo, se detectó illita $\mathrm{y}$, en algunas muestras, esmectita

(3) Esta similitud con Casa Montero refuerza la asignación cronológica de La Deseada al VI milenio AC. 

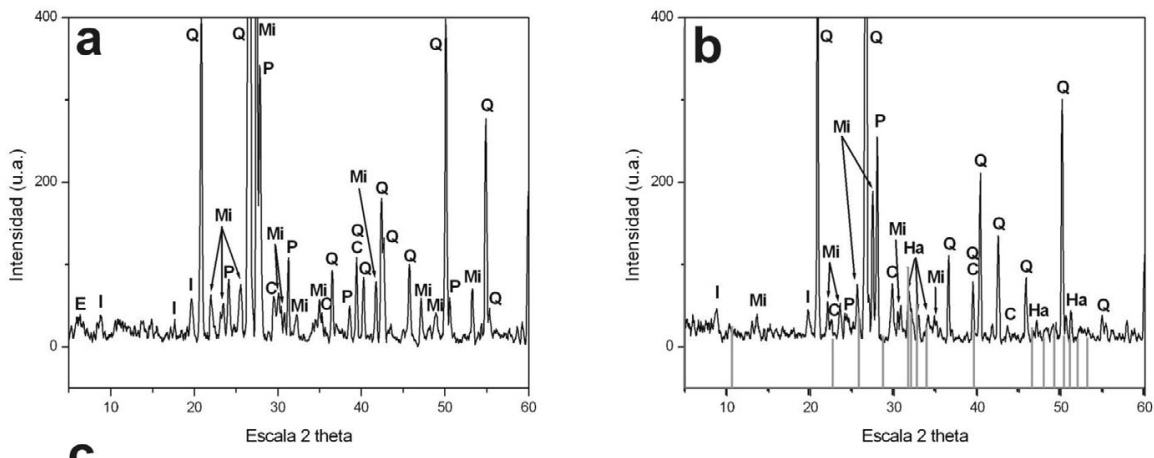

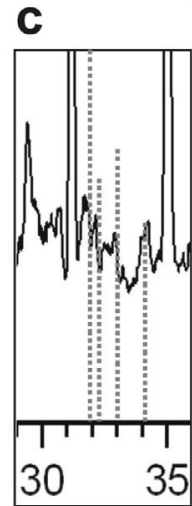

Muestra 9 34 inclusiones

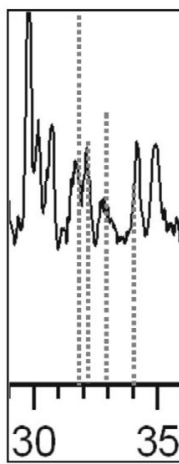

Muestra 26

85 inclusiones

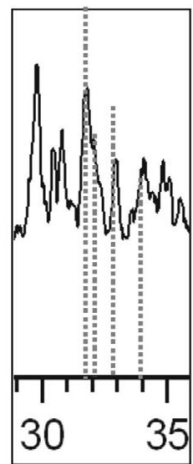

Muestra 19 93 inclusiones

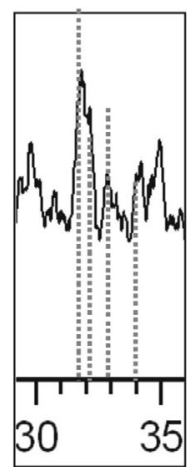

Muestra 4 104 inclusiones

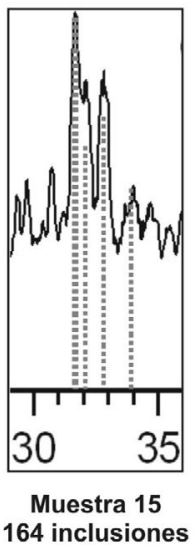

Fig. 5. Difractogramas. a) Fragmento cerámico sin inclusiones de hueso. Muestra 1. b) Fragmento cerámico con inclusiones de hueso. Muestra 19. Se señalan las reflexiones características de la fase hidroxiapatita (ficha JCPDS núm. 24-0033. c) Detalle del intervalo $2 \theta=30-35^{\circ}$ en el que aparecen las principales reflexiones de la fase hidroxiapatita, según el número de inclusiones de hueso determinadas en lámina delgada. C. Calcita. E. Esmectita. Ha. Hidroxiapatita. I. Illita. Mi. Microclina (feldespato potásico). P. Plagioclasa (feldespato sódico). Q. Cuarzo. Procedencia y cronología de las muestras en tabla 1.

como fases secundarias relacionadas con la matriz arcillosa, así como pequeñas proporciones de calcita que, según la observación petrográfica, podría ser en su mayoría de aporte externo (Fig. 5a). El análisis del sedimento arcilloso cocido en laboratorio a $750{ }^{\circ} \mathrm{C}$ (muestra 29) confirmó que no era compatible mineralógicamente con los fragmentos cerámicos, ya que en su difractograma se detectó esmectita como fase mayoritaria y, en mucha menor medida, microclina e illita (4).

A partir de los datos de DRX se puede estimar una temperatura de cocción equivalente para los fragmentos cerámicos analizados de unos $700-750{ }^{\circ} \mathrm{C}$. Esta estimación se basa en el hecho de que todavía se detectan reflexiones de illita y esmectita, minerales arcillosos que no pierden su

(4) García-Heras et al. en nota a pie 1, figura 1C. estructura cristalina hasta temperaturas próximas a los $850{ }^{\circ} \mathrm{C}$ (Rice 1987: 92). La estructura cristalina en illitas y esmectitas se corrobora con los datos de la observación petrográfica en la que no se detectaron signos de vitrificación en las matrices arcillosas.

\subsubsection{Caracterización de las inclusiones de hueso}

En todas las muestras con inclusiones de hueso se determinó la fase hidroxiapatita, que es un fosfato de calcio $\left[\mathrm{Ca}_{5}\left(\mathrm{PO}_{4}\right)_{3}(\mathrm{OH})\right]$ y es el componente inorgánico mayoritario del hueso $(\sim 40 \%)$. Este dato demuestra que efectivamente se trata de hueso añadido al material cerámico. La figura $5 \mathrm{~b}$ presenta, como ejemplo, el difractograma de la muestra 19 , donde se contabilizaron un 
total de 93 inclusiones, con tamaños próximos a $1,0 \mathrm{~mm}$. En esta muestra se detectaron, junto a las otras fases mineralógicas, casi la totalidad de las reflexiones características de la hidroxiapatita, según la ficha núm. 24-0033 del JCPDS. Las reflexiones principales de esta fase tienen lugar en el intervalo comprendido entre $2 \theta=30-35^{\circ}$ (aproximadamente a $31,7^{\circ} ; 32,1^{\circ} ; 32,8^{\circ}$ y $33,9^{\circ}$ ). Un estudio exhaustivo de esta región del difractograma permitió comprobar que su poder reflectante y, por tanto, su mejor determinación, es más elevado cuanto mayor es el número de inclusiones de hueso presentes en el fragmento cerámico (Fig. 5c). Así, se puede establecer una progresión de menor a mayor poder reflectante entre la muestra 9, con 34 inclusiones de hueso y la muestra 15, con 164. En las muestras en las que se contabilizó un número de inclusiones inferior a 34 , no fue posible la identificación precisa de hidroxiapatita a partir de sus reflexiones principales, debido a que se confundían con el ruido de fondo de la línea base del difractograma.

\subsubsection{Comportamiento térmico de la hidroxiapatita}

Cuando se calcina el hueso en atmósfera oxidante las reflexiones principales de la fase hidroxiapatita en el intervalo $2 \theta=30-35^{\circ}$ varían según la temperatura alcanzada. Así, las reflexiones a $2 \theta=31,7^{\circ} ; 32,1^{\circ}$ y $32,8^{\circ}$ respectivamente, se van separando a medida que aumenta la temperatura. A temperatura ambiente las dos primeras reflexiones no pueden distinguirse y la tercera es sólo un hombro. A temperaturas comprendidas entre $700-750{ }^{\circ} \mathrm{C}$, las dos primeras reflexiones se solapan y se diferencian de la tercera, mientras que si la temperatura se aproxima a los $800-850{ }^{\circ} \mathrm{C}$ se distinguen las tres reflexiones y no se produce ningún solapamiento entre ellas (Rogers y Daniels 2002; Odriozola y Hurtado 2007).

Con el propósito de comprobar el comportamiento térmico de la hidroxiapatita en los fragmentos cerámicos con inclusiones de hueso, se seleccionó la muestra 15, con 164 contabilizadas, para su recocción en laboratorio a $900{ }^{\circ} \mathrm{C}(5)$.

(5) Se recoció en un horno eléctrico en atmósfera oxidante a $900{ }^{\circ} \mathrm{C}$, siguiendo el mismo procesado térmico que para el sedimento arcilloso de Casa Montero. La única diferencia fue que la temperatura se elevó desde $300{ }^{\circ} \mathrm{C}$ hasta $900{ }^{\circ} \mathrm{C}$ en 96 min.
En los fragmentos cerámicos con hueso las dos primeras reflexiones $\left(2 \theta=31,7^{\circ}\right.$ y $\left.32,1^{\circ}\right)$ aparecieron solapadas en casi todas (Fig. 5c), incluida la muestra 15 (Fig. 6a), independientemente del número de inclusiones de hueso contabilizadas. Por el contrario, en el difractograma de la muestra 15 recocida a $900{ }^{\circ} \mathrm{C}$ (Fig. 6b), se distinguen las tres reflexiones sin que se produzca ningún solapamiento entre ellas. Este dato, por tanto, indica que los fragmentos cerámicos con inclusiones de hueso también debieron cocerse a una temperatura equivalente de unos $700-750{ }^{\circ} \mathrm{C}$, habida cuenta de que prácticamente en ninguno de ellos se pudo distinguir de forma precisa una separación entre las dos primeras reflexiones principales de la fase hidroxiapatita a $2 \theta=31,7^{\circ}$ y $32,1^{\circ}$, respectivamente.

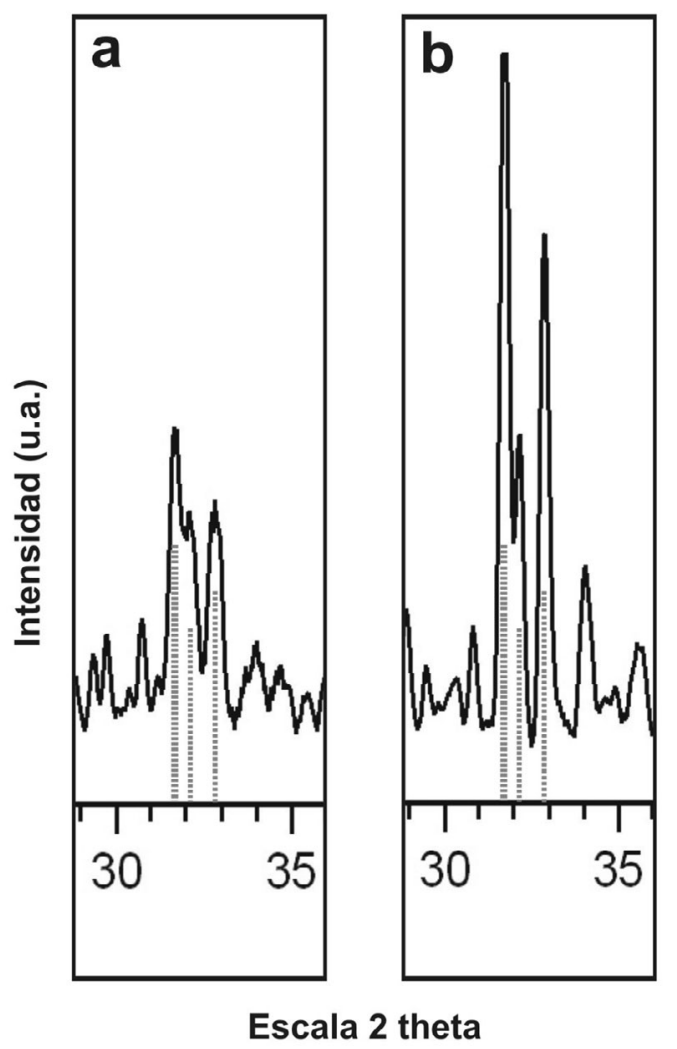

Fig. 6. Detalle del intervalo $2 \theta=30-35^{\circ}$ de los difractogramas de la muestra 15 con inclusiones de hueso. a) Fragmento cerámico como se recibió en el laboratorio. b) Fragmento cerámico recocido a $900{ }^{\circ} \mathrm{C}$ en atmósfera oxidante. Procedencia y cronología de las muestras en tabla 1 . 


\subsection{Observaciones microestructurales mediante MEB}

La observación microestructural realizada sobre la fractura fresca de los fragmentos cerámicos no determinó ninguna diferencia entre las matrices arcillosas de aquellos fragmentos con inclusiones de hueso (Fig. 7a) y sin ellos (Fig. 7b). En ambos casos las matrices mostraron una microestructura laminar que puede asociarse a un estado de sinterización que no ha alcanzado la vitrificación (García-Heras y Rincón 1996). Los cristales de los minerales arcillosos, compuestos mayoritariamente por illita, todavía no han comenzado a sinterizarse como resultado de una temperatura de cocción relativamente baja. Esta microestructura confirmó las observaciones petrográficas y los datos de DRX, en los que se detectaron las reflexiones características de la illita debido a que todavía no había perdido su estructura cristalina por efecto de una baja temperatura de cocción.

Las observaciones mediante MEB confirmaron la adición intencionada de hueso a las cerámicas, puesto que estas inclusiones presen-
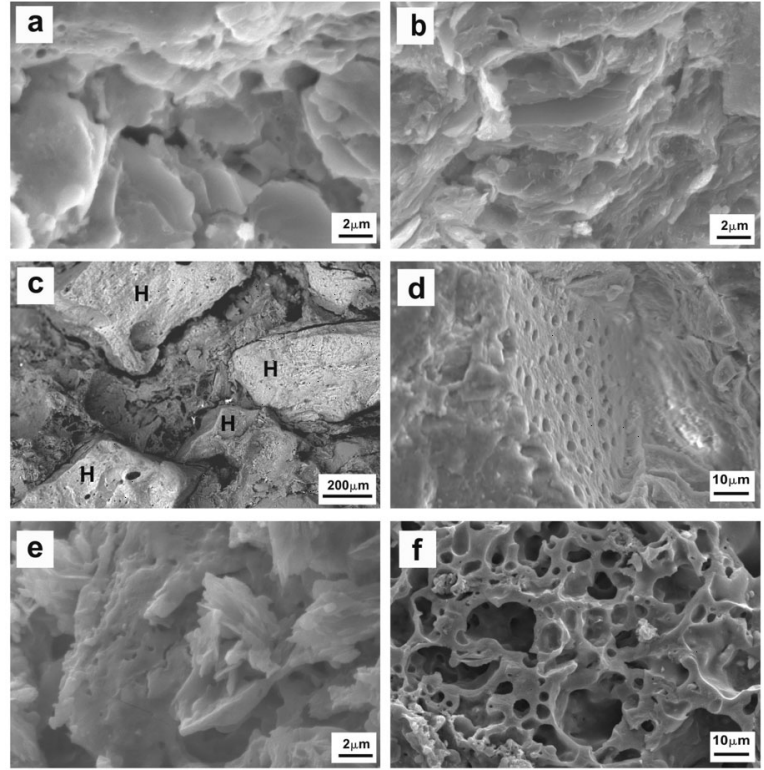

Fig. 7. Micrografías de MEB sobre fracturas frescas. Electrones secundarios (a-b-d-e-f). Electrones retrodispersados (c). a) Microestructura de la muestra 7. b) Microestructura de la muestra 8. c) Inclusiones de hueso (H) en la muestra 3. d) Detalle de los osteocitos en la muestra 3. e-f) Microestructuras de la muestra 17. Procedencia y cronología de las muestras en tabla 1. taron siempre contactos limpios y bien delimitados con la matriz arcillosa circundante (Fig. 7c). Las observaciones también sirvieron para detallar mejor los osteocitos y los canales vasculares circulares característicos de la estructura ósea (Fig. 7d).

El estudio de la muestra 17, correspondiente a un gran recipiente de El Congosto, requirió una observación pormenoriza tanto del interior de la matriz como de la superficie externa que presentó una zona con evidencias de vitrificación. La microestructura laminar de la matriz (Fig. 7e) era muy similar a la del resto de los fragmentos cerámicos, que también puede asociarse a un estado de sinterización que no ha alcanzado la vitrificación. En el difractograma obtenido en esta zona se identificaron las fases cuarzo, feldespatos (plagioclasa y microclina) y calcita, que se correspondieron con las observaciones petrográficas mediante lámina delgada. La microestructura exhibió un estado sin inicios de vitrificación, pero no se detectaron reflexiones de ningún mineral arcilloso, lo cual confirmó que la matriz era más arenosa y calcárea que la del resto de los fragmentos cerámicos, como ya se observó mediante lámina delgada. Por el contrario, la microestructura celular de la superficie externa puede asociarse a un estado de sinterización con inicio de vitrificación (Fig. 7f). Dicha microestructura se debe al escape de burbujas de $\mathrm{CO}_{2}$ que se producen cuando se descomponen los carbonatos como la calcita por efecto de una temperatura elevada. Este hecho se confirmó en el difractograma obtenido en esta zona en el que, a las fases presentes también en la matriz interna, se unieron tres fases de alta temperatura: anortita, diópsido y gehlenita. La anortita y la gehlenita se forman por reacción de los silicatos con los cationes de calcio liberados en la descomposición de la calcita. Ésta comienza a partir de los $750{ }^{\circ} \mathrm{C}$ y la formación de anortita y gehlenita tiene lugar entre 850 y $900{ }^{\circ} \mathrm{C}$ (Maggetti 1982: 128). Por otro lado, el diópsido se forma por reacción de los silicatos con los cationes de magnesio liberados en la descomposición de carbonatos mixtos, a partir de $800-850{ }^{\circ} \mathrm{C}$ (Linares et al. 1983). Estas tres fases indican que en la superficie de este gran recipiente se produjo un episodio de alta temperatura, en el que se alcanzaron al menos $900^{\circ} \mathrm{C}$, quizá bastante puntual porque el espesor de la zona con inicios de vitrificación no supera los $3 \mathrm{~mm}$, en una pared cuyo espesor total es de unos $33 \mathrm{~mm}$. 


\subsection{Análisis de la "almagra" mediante DRX convencional y de ángulo rasante, $\mathrm{MEB}$ y microanálisis EDS}

De los 6 fragmentos cerámicos con "almagra" seleccionados, la muestra 10 de La Deseada tenía una almagra de color rojo más intenso y, en general, mejor estado de conservación. En las restantes 5 el color era rojo más apagado y el estado de conservación peor, con abundantes depósitos calcáreos blanquecinos (Fig. 4d). En estas muestras se llevó a cabo el análisis mediante DRX convencional en el cuerpo del fragmento cerámico y mediante ángulo rasante en su superficie externa, para determinar sus diferencias mineralógicas. Asimismo, se observaron mediante MEB y microanálisis EDS en secciones pulidas para determinar sus características microestructurales y su composición química, respectivamente.

En el difractograma del cuerpo del fragmento de la muestra 10 (Fig. 8a) sólo se detectaron dos fases principales: cuarzo y calcita; y una secundaria: illita. Estos resultados confirmaron las observaciones petrográficas y redundan en la posible procedencia foránea de la cerámica. Por el contrario, en el difractograma mediante ángulo rasante obtenido sobre la superficie externa (Fig. 8b), se detectó cuarzo como fase principal y calcita y hematita como fases secundarias. Ello podría indicar que la "almagra" se compone de ocre rico en óxido de hierro, debido a la presencia de hematita sólo detectada en la superficie, que proporcionó la coloración roja intensa a la capa externa. El cuarzo y la calcita se detectaron también en el cuerpo del fragmento, pero no se puede descartar que parte de estas fases mineralógicas sean impurezas del ocre empleado en la elaboración de la "almagra". La microestructura de la capa de "almagra", de unos $40 \mu \mathrm{m}$ de espesor medio, no presentó signos de vitrificación ni diferencias apreciables respecto a la matriz arcillosa del fragmento (Fig. 8c), lo que podría indicar que se densificó térmicamente al mismo tiempo que la pieza cerámica y no en cocciones diferentes. El microanálisis EDS en línea y determinó un contenido en hierro en la microestructura de la "almagra" mucho más elevado que en el cuerpo del fragmento cerámico, lo que corrobora la identificación de hematita mediante DRX.

En todas las muestras restantes con "almagra" se identificaron inclusiones de hueso en la observación petrográfica (Tab. 1). Por ello, en los di- fractogramas correspondientes se detectó siempre la fase hidroxiapatita (Fig. 8d). Los análisis mediante DRX con ángulo rasante determinaron que la "almagra", en estos casos, podría estar constituida por un engobe compuesto por ocre mezclado con una arcilla ilítico-caolinítica que contribuiría a atenuar el color rojo intenso. El ocre se asoció a la presencia de hematita, mientras que la arcilla se determinó a partir de las fases illita y caolinita (Fig. 8e). Como las fases mineralógicas se detectaron en la superficie (cuarzo, plagioclasa, microclina y calcita) y en el cuerpo del fragmento cerámico, no podemos determinar si formaban o no parte del engobe. No obstante, en la superficie de los fragmentos se detectó una mayor cantidad de calcita que en su interior por la presencia de depósitos calcáreos. En estos 5 fragmentos el espesor medio de la capa de "almagra" fue considerablemente menor (unos $10 \mu \mathrm{m}$ ) que el observado en la muestra 10 de La Deseada. Su microestructura tampoco presentó signos de vitrificación ni diferencias apreciables respecto a la matriz arcillosa de los fragmentos (Fig. 8f). Estos datos indican, igualmente, que los engobes también se densificaron térmicamente al mismo tiempo que las piezas cerámicas. La presencia de reflexiones de minerales arcillosos como la illita o la caolinita sugiere, además, una baja temperatura de cocción. Los microanálisis de EDS en línea determinaron también un contenido en hierro en la microestructura de la "almagra" mucho más elevado que en el cuerpo del fragmento cerámico. Asimismo, se comprobó que en los depósitos externos el componente principal era calcio, que se correlaciona con la identificación de calcita micrítica en la observación petrográfica (Fig. 4d).

La "almagra" de La Deseada se componía casi exclusivamente de ocre rico en hematita. En cambio, la "almagra" de los cinco fragmentos restantes se elaboró muy probablemente con un ocre mezclado con arcilla, lo que produjo un engobe de un color rojo poco intenso y escaso espesor más que una verdadera capa de "almagra" (Capel et al. 2006).

\subsection{Composición química y análisis estadístico}

Los resultados del análisis químico en masa mediante FRX presentaron dos peculiaridades importantes que fue necesario tener en cuenta an- 

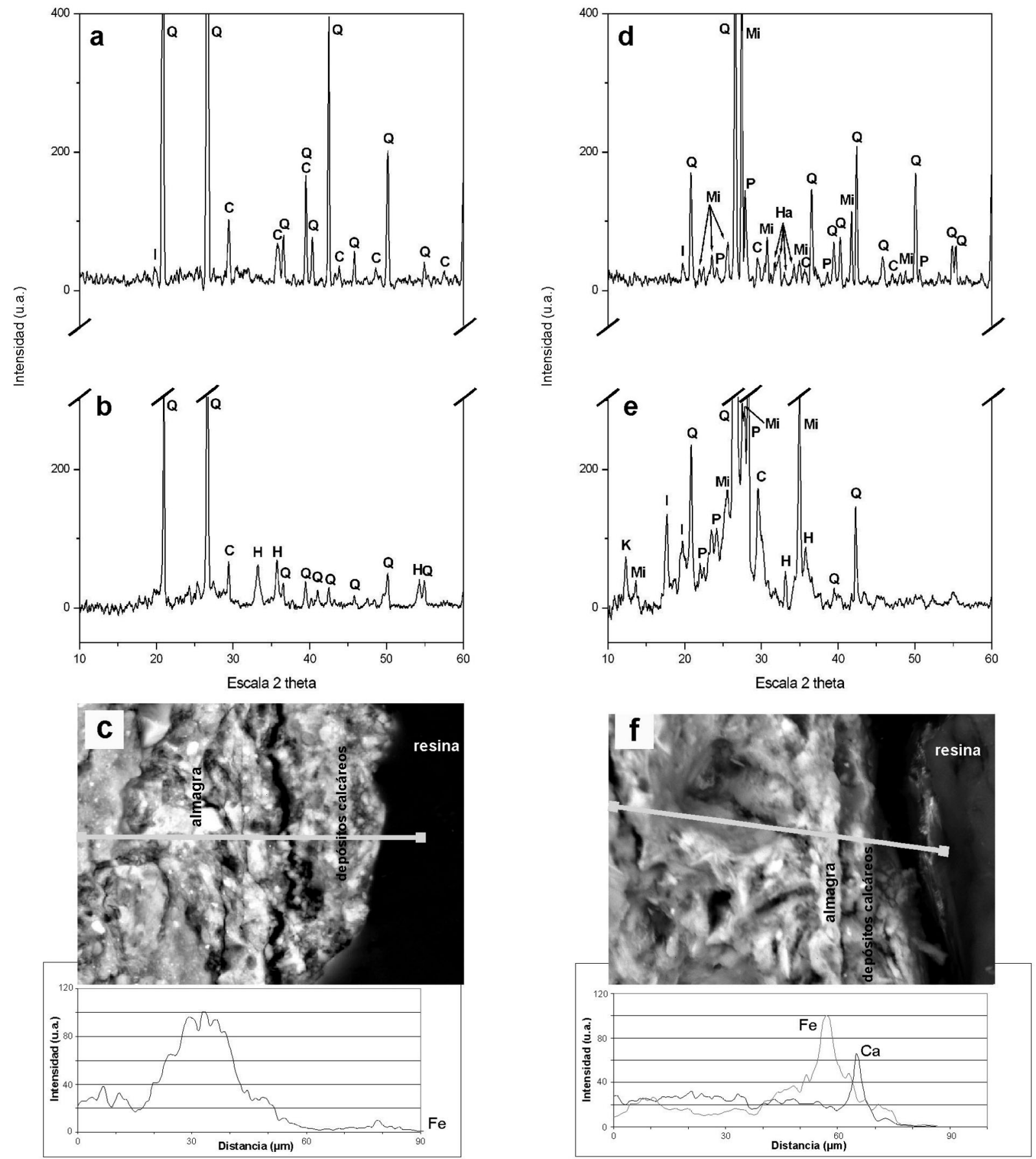

Fig. 8. Fragmentos con “almagra”. Muestras 10 (a-b-c), 6 (d-e) y 3 (f). a) Difractograma del interior del fragmento. b) Difractograma con ángulo rasante de la superficie del fragmento. c) Barrido en línea por MEB/EDS en una sección pulida del fragmento. Micrografía con electrones secundarios. d) Difractograma del interior del fragmento. e) Difractograma con ángulo rasante de la superficie del fragmento. f) Barrido en línea por MEB/EDS en una sección pulida del fragmento. Micrografía con electrones secundarios. C. Calcita. H. Hematita. Ha. Hidroxiapatita. I. Illita. K. Caolinita. Mi. Microclina (feldespato potásico). P. Plagioclasa (feldespato sódico). Q. Cuarzo. Procedencia y cronología de las muestras en tabla 1. 
tes del análisis estadístico de los datos. Por un lado, los resultados de FRX determinaron, como las observaciones petrográficas y los análisis por DRX, que la composición química del sedimento arcilloso procedente de Casa Montero (muestra 29) es muy distinta a la de los fragmentos cerámicos. Ello sugiere nuevamente que no se utilizó un sedimento de estas características para la elaboración de la cerámica analizada. Por otro, que la composición química en masa se corresponde con el material en su conjunto. Esto significa que en las cerámicas en las que se añadió hueso como desgrasante, según demostraron los datos petrográficos, de DRX y las observaciones mediante MEB, sufrirán una alteración en su composición química original. Como el componente inorgánico principal del hueso es la hidroxiapatita, que es un fosfato de calcio, la composición determinada en las cerámicas reflejará también esta adición. Este hecho se constató en el enriquecimiento generalizado de los contenidos de óxido de calcio y óxido de fósforo, los cuales se hallaron correlacionados con el número de inclusiones de hueso contabilizadas en la observación petrográfica. Los contenidos más bajos del óxido de fósforo (Fig. 9a) se determinaron en
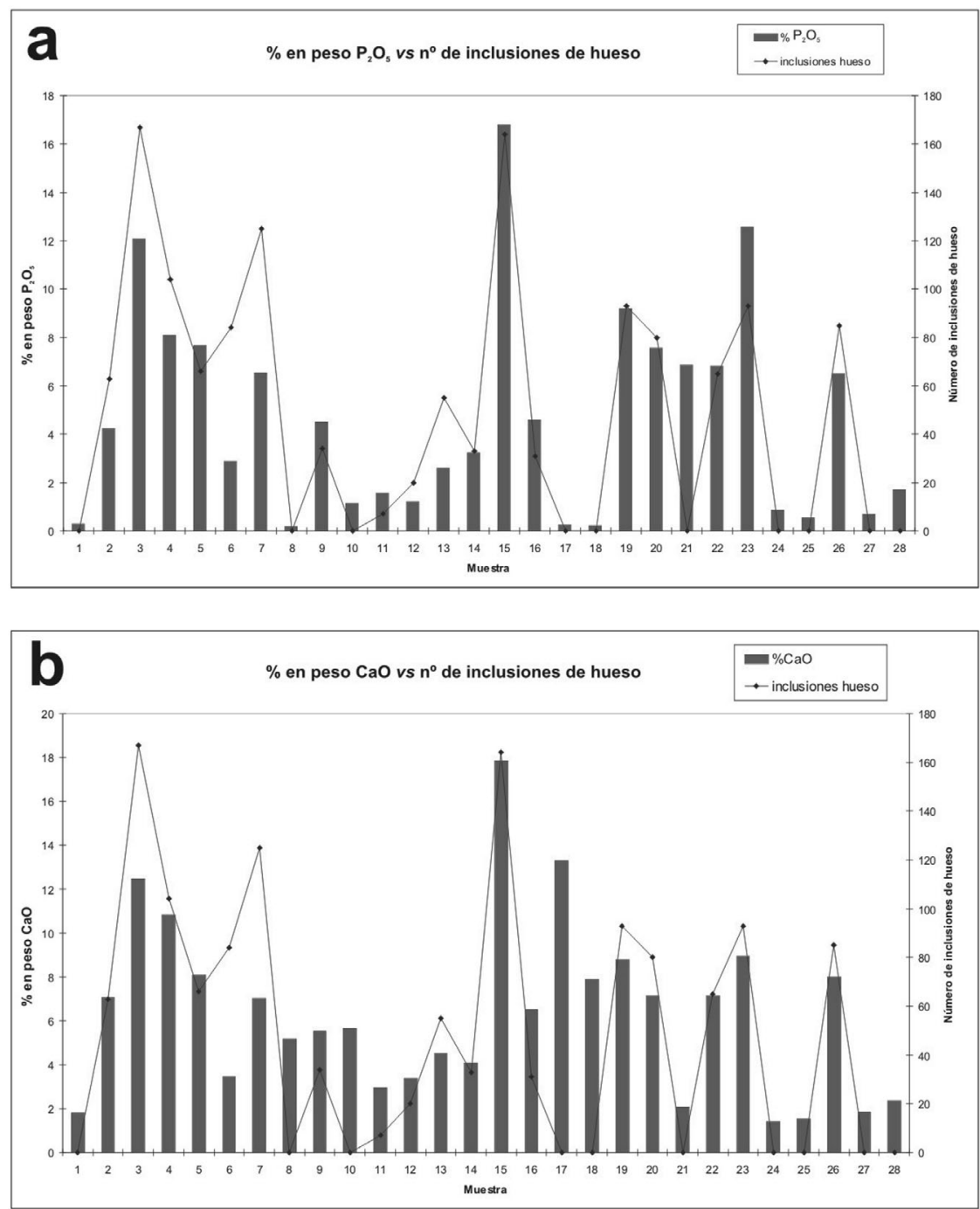

Fig. 9. Relación entre el número de inclusiones de hueso determinadas en lámina delgada y la concentración (\% en peso) de óxido de fósforo (a) y de óxido de calcio (b) determinados por FRX. 
aquellas muestras en las que no se detectó hueso $(1,8,10,17,18,24,25,27$ y 28$)$, con la excepción de la muestra 21 donde su porcentaje elevado de este óxido podría explicarse por la presencia de restos de fibras vegetales. La muestra 15, en la que se contabilizaron 164 inclusiones (Tab. 1), es la de mayor concentración de óxido de fósforo. Los contenidos del óxido de calcio (Fig. 9b) más elevados se determinaron, en general, en las muestras con mayor presencia de inclusiones de hueso, como la muestra 15 . Sin embargo, en la concentración de este óxido también intervienen factores, como la presencia de calcita secundaria de aporte externo o de calcita presente en la propia matriz del fragmento cerámico (muestras 10, 17 y 18). Hay que resaltar que las inclusiones de hueso añadido no se hubieran detectado si no se hubiera realizado la observación petrográfica mediante lámina delgada y la combinación de otras técnicas químico-físicas de caracterización arqueométrica, lo cual habría incidido negativamente en la correcta interpretación de la composición química de las muestras.

Dadas las dos peculiaridades comentadas, el análisis estadístico de los datos de composición química obtenidos mediante FRX eliminó la muestra 29 y las concentraciones de los óxidos de calcio y de fósforo. Una vez eliminados ambos, se renormalizó a 100 el contenido de los diez óxidos restantes determinados. Así pues, el análisis estadístico se llevó a cabo sobre 28 muestras utilizando las concentraciones transformadas en valores logarítmicos de las 10 variables siguientes: $\mathrm{Na}_{2} \mathrm{O}, \mathrm{MgO}, \mathrm{Al}_{2} \mathrm{O}_{3}, \mathrm{SiO}_{2}, \mathrm{~K}_{2} \mathrm{O}, \mathrm{TiO}_{2}, \mathrm{MnO}$, $\mathrm{Fe}_{2} \mathrm{O}_{3}$, SrO y $\mathrm{BaO}$.

El análisis de componentes principales, basado en una matriz de varianza-covarianza, proporcionó una estructura en la que una parte importante de las muestras (17 en total) se asoció a una única agrupación, quedando las restantes desagrupadas. La distinción de esta agrupación se ilustra en la figura 10, donde se representan las muestras según su puntuación en los dos primeros componentes, que sumaron el $63,79 \%$ de la variación total en los datos. En el primer componente, que explicó un 35,77\% de la variación, las variables $\mathrm{SrO}, \mathrm{MgO}$ y $\mathrm{MnO}$ se correlacionaron de forma positiva, mientras que las variables $\mathrm{SiO}_{2}$ y $\mathrm{K}_{2} \mathrm{O}$ lo hicieron, sobre todo, de manera negativa. En el segundo componente, con un $28,02 \%$ de la variación, fueron las variables $\mathrm{BaO}, \mathrm{SrO}$ y $\mathrm{Fe}_{2} \mathrm{O}_{3}$ las que se correlacionaron principalmente de for-

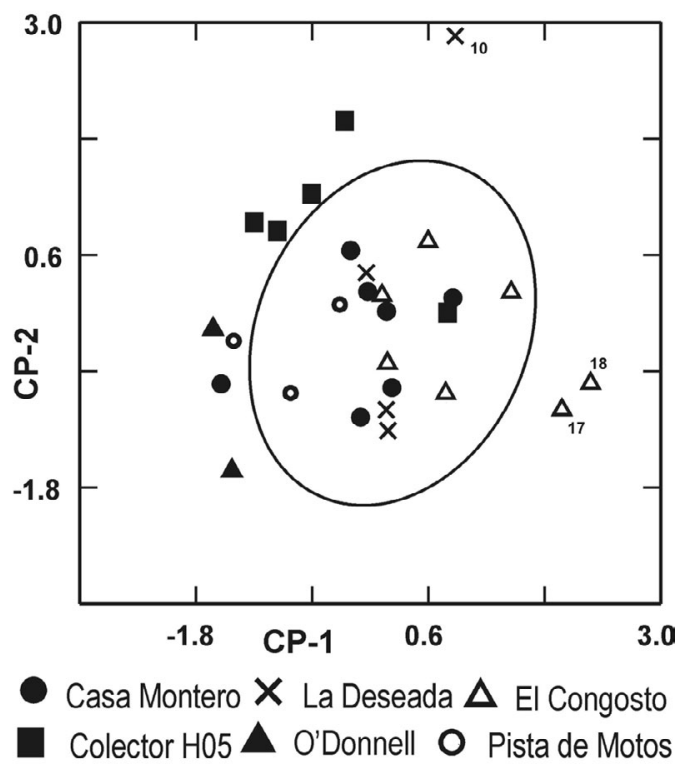

Fig. 10. Representación de las muestras y su agrupación según la puntuación en los dos primeros componentes principales. La elipse representa el $95 \%$ de confidencia de pertenencia al grupo. Se señala la posición de las muestras 10 ("almagra" de La Deseada), 17 y 18 (grandes recipientes de El Congosto). Procedencia y cronología de las muestras en tabla 1.

ma positiva, mientras que las variables $\mathrm{MgO}$, $\mathrm{MnO}$ y $\mathrm{K}_{2} \mathrm{O}$ se correlacionaron negativamente (Tab. 3).

La validez estadística de la única agrupación obtenida en el análisis de componentes principales se estimó a partir de un análisis canónico discriminante en el que también se calcularon las distancias de Mahalanobis de cada muestra con respecto al centroide de la agrupación (Baxter 1994). Los resultados de este análisis confirmaron la agrupación establecida, así como la existencia de 11 muestras que no pertenecían a dicha agrupación. Las 17 muestras asociadas al grupo presentaron al menos un $95 \%$ de probabilidad de pertenencia al mismo. En cuanto a las distancias de Mahalanobis, el grupo se mostró bastante homogéneo, ya que sus puntuaciones se situaron entre 1,5 y 17,4 respecto a su centroide. La tabla 4 ofrece los valores promedio y las desviaciones estándar del grupo obtenido en el análisis estadístico de los datos de FRX (Grupo 1), junto a los valores obtenidos para todas las muestras analizadas.

El Grupo 1 (Fig. 10) se compone de: las muestras de Casa Montero excepto la muestra 1, sin inclusiones de hueso; las muestras de La Deseada, 


\begin{tabular}{|c|c|c|c|c|c|c|c|c|c|c|}
\hline $\begin{array}{l}\text { Compo- } \\
\text { nente } \\
\text { principal }\end{array}$ & $\mathrm{Na}_{2} \mathrm{O}$ & MgO & $\mathbf{A l}_{2} \mathbf{O}_{3}$ & $\mathrm{SiO}_{2}$ & $\mathbf{K}_{2} \mathbf{O}$ & $\mathrm{TiO}_{2}$ & MnO & $\mathrm{Fe}_{2} \mathrm{O}_{3}$ & SrO & $\mathrm{BaO}$ \\
\hline 1 & 0,004 & 0,095 & 0,004 & $-0,010$ & $-0,004$ & 0,038 & 0,051 & 0,045 & 0,247 & 0,041 \\
\hline 2 & $-0,068$ & $-0,135$ & 0,007 & 0,001 & $-0,075$ & 0,019 & $-0,132$ & 0,038 & 0,052 & 0,102 \\
\hline
\end{tabular}

Tab. 3. Peso de las variables según los dos primeros componentes principales del análisis estadístico.

\begin{tabular}{|c|c|c|c|c|c|c|c|c|c|c|c|}
\hline $\begin{array}{l}\text { Muestra } \\
\text { o grupo }\end{array}$ & Yacimiento & $\mathrm{Na}_{2} \mathrm{O}$ & MgO & $\mathbf{A l}_{2} \mathbf{O}_{3}$ & $\mathrm{SiO}_{2}$ & $\mathbf{K}_{2} \mathbf{O}$ & $\mathrm{TiO}_{2}$ & MnO & $\mathrm{Fe}_{2} \mathrm{O}_{3}$ & SrO & $\mathrm{BaO}$ \\
\hline $\begin{array}{c}\text { Grupo } 1 \\
(\mathrm{~N}=17)\end{array}$ & & & & & & & & & & & \\
\hline Media & & 0,91 & 2,44 & 20,05 & 65,25 & 4,74 & 0,69 & 0,06 & 5,72 & 0,06 & 0,09 \\
\hline Des. st. & & 0,31 & 0,60 & 1,90 & 3,70 & 0,70 & 0,14 & 0,02 & 1,47 & 0,03 & 0,04 \\
\hline 1 & Casa Montero & 1,09 & 1,78 & 18,22 & 69,86 & 4,39 & 0,49 & 0,05 & 4,03 & 0,02 & 0,06 \\
\hline 2 & Casa Montero & 0,74 & 3,09 & 19,77 & 64,50 & 4,50 & 0,80 & 0,08 & 6,42 & 0,04 & 0,06 \\
\hline 3 & Casa Montero & 1,04 & 3,09 & 18,12 & 68,09 & 4,43 & 0,57 & 0,04 & 4,42 & 0,09 & 0,10 \\
\hline 4 & Casa Montero & 0,70 & 2,62 & 21,04 & 65,88 & 3,38 & 0,69 & 0,03 & 4,50 & 0,05 & 0,11 \\
\hline 5 & Casa Montero & 1,22 & 2,02 & 20,81 & 65,07 & 5,07 & 0,63 & 0,04 & 4,98 & 0,07 & 0,09 \\
\hline 6 & Casa Montero & 1,00 & 3,37 & 20,50 & 65,28 & 4,26 & 0,59 & 0,06 & 4,80 & 0,05 & 0,09 \\
\hline 7 & Casa Montero & 0,95 & 1,81 & 19,52 & 67,28 & 4,81 & 0,57 & 0,05 & 4,83 & 0,05 & 0,12 \\
\hline 8 & La Deseada & 0,61 & 2,16 & 21,70 & 65,03 & 4,11 & 0,84 & 0,04 & 5,38 & 0,05 & 0,08 \\
\hline 9 & La Deseada & 1,60 & 2,39 & 17,56 & 67,62 & 5,20 & 0,66 & 0,06 & 4,80 & 0,06 & 0,05 \\
\hline 10 & La Deseada & 0,54 & 1,00 & 20,90 & 63,17 & 1,10 & 1,08 & 0,03 & 11,95 & 0,12 & 0,11 \\
\hline 11 & La Deseada & 1,23 & 3,01 & 19,48 & 63,24 & 5,66 & 0,75 & 0,06 & 6,47 & 0,05 & 0,05 \\
\hline 12 & El Congosto & 0,64 & 2,33 & 19,25 & 65,60 & 5,17 & 0,70 & 0,07 & 6,12 & 0,06 & 0,06 \\
\hline 13 & El Congosto & 0,85 & 2,45 & 19,83 & 65,84 & 4,71 & 0,66 & 0,05 & 5,45 & 0,05 & 0,11 \\
\hline 14 & El Congosto & 1,26 & 2,38 & 18,39 & 68,33 & 4,58 & 0,53 & 0,07 & 4,30 & 0,10 & 0,06 \\
\hline 15 & El Congosto & 1,08 & 1,98 & 19,77 & 62,58 & 6,25 & 0,77 & 0,06 & 7,28 & 0,14 & 0,10 \\
\hline 16 & El Congosto & 0,45 & 2,13 & 18,50 & 68,54 & 3,80 & 0,64 & 0,04 & 5,73 & 0,09 & 0,07 \\
\hline 17 & El Congosto & 1,00 & 3,93 & 20,04 & 62,72 & 4,66 & 0,79 & 0,11 & 6,53 & 0,14 & 0,08 \\
\hline 18 & El Congosto & 1,37 & 2,72 & 18,95 & 65,74 & 5,11 & 0,64 & 0,09 & 5,08 & 0,24 & 0,07 \\
\hline 19 & Colector H05 & 0,78 & 0,91 & 19,15 & 68,79 & 4,35 & 0,61 & 0,04 & 5,21 & 0,05 & 0,11 \\
\hline 20 & Colector H05 & 0,91 & 0,91 & 18,52 & 69,51 & 4,77 & 0,53 & 0,03 & 4,70 & 0,04 & 0,09 \\
\hline 21 & Colector H05 & 0,50 & 3,46 & 25,97 & 52,62 & 5,47 & 1,13 & 0,09 & 10,51 & 0,05 & 0,21 \\
\hline 22 & Colector H05 & 0,74 & 1,18 & 18,94 & 68,60 & 4,77 & 0,58 & 0,03 & 5,05 & 0,04 & 0,08 \\
\hline 23 & Colector H05 & 0,88 & 0,73 & 22,03 & 64,63 & 4,72 & 0,71 & 0,03 & 6,03 & 0,06 & 0,18 \\
\hline 24 & O’Donnell & 1,02 & 1,28 & 19,46 & 68,37 & 4,51 & 0,59 & 0,04 & 4,67 & 0,02 & 0,05 \\
\hline 25 & O’Donnell & 0,99 & 2,46 & 20,77 & 65,21 & 4,22 & 0,69 & 0,10 & 5,50 & 0,02 & 0,05 \\
\hline 26 & Pista de Motos & 0,79 & 1,79 & 19,35 & 68,03 & 4,40 & 0,59 & 0,04 & 4,88 & 0,05 & 0,07 \\
\hline 27 & Pista de Motos & 1,01 & 1,63 & 18,32 & 69,28 & 4,55 & 0,57 & 0,04 & 4,52 & 0,03 & 0,06 \\
\hline 28 & Pista de Motos & 0,81 & 1,33 & 21,21 & 65,75 & 4,73 & 0,65 & 0,12 & 5,30 & 0,03 & 0,07 \\
\hline 29 & Casa Montero & 0,12 & 23,24 & 6,90 & 65,60 & 1,60 & 0,37 & 0,01 & 2,12 & 0,02 & 0,02 \\
\hline
\end{tabular}

Tab. 4. Resultados del análisis químico mediante espectrometría de FRX (\% en peso). Des. st. Desviación estándar.

excepto la muestra 10 con "almagra"; las muestras de El Congosto, excepto las dos pertenecientes a grandes recipientes (muestras 17 y 18); la muestra 21 de Colector H05 perteneciente también a un gran recipiente; y dos de las tres muestras de Pista de Motos. A partir de esta agrupa- ción y de las muestras que no se asocian a la misma, pueden señalarse los siguientes aspectos:

1) Los fragmentos cerámicos procedentes de los yacimientos de cronología más antigua como Casa Montero, La Deseada y El Congosto, con la excepción de dos de las muestras de Pista de Mo- 
tos, tienen una composición química muy similar, lo que indica que se elaboraron probablemente con sedimentos arcillosos muy semejantes. Entre estos yacimientos no es posible diferenciar químicamente la mayor parte de sus cerámicas.

2) Las cerámicas de Colector $\mathrm{H} 05$ y O'Donnell se elaboraron con sedimentos ligeramente distintos a los empleados en la cerámica de los yacimientos de cronología más antigua. Esto podría indicar que las fuentes de materia prima cambiaron con el tiempo o que en estos yacimientos se utilizaran otras distintas dada su ubicación en otra cuenca fluvial.

3) Las cerámicas con inclusiones de hueso añadido no parecen tener una cronología concreta puesto que se identificaron en todos los yacimientos excepto en O'Donnell.

4) La muestra 10 con "almagra" de La Deseada es de procedencia foránea como se desprende de su composición química, la cual es claramente distinta de la del resto de muestras analizadas (Fig. 10). Su contenido en óxido de hierro es el más elevado (11,95\% en peso), mientras que la concentración de óxido de potasio es la más reducida (1,10\% en peso) (Tab. 4). La adición de un número considerable de inclusiones de chamota puede haber influido en su composición química.

5) Las muestras con chamota de Casa Montero y La Deseada no presentaron una composición química muy distinta a la del resto de los fragmentos cerámicos de estos yacimientos, puesto que se asociaron al Grupo 1. Este hecho podría indicar que la cerámica machacada y añadida al sedimento arcilloso era la que se elaboraba habitualmente.

6) Las muestras con "almagra" de Casa Montero y Congosto se asocian al Grupo 1, lo que indica que no difieren en composición química con respecto a las otras muestras. Esto es, no se utilizó una materia prima distinta para elaborar las "almagras" de origen local.

7) Las muestras 8 y 21 de grandes recipientes se elaboraron con sedimentos de igual composición química que el resto de las cerámicas, aunque el examen petrográfico indicó que se manufacturaron con sedimentos de textura más fina. Sin embargo, las muestras 17 y 18 de El Congosto (Fig. 10) se elaboraron con materias primas distintas a las empleadas para el resto de las cerámicas de este yacimiento.

\section{IMPLICACIONES TECNOLÓGICAS Y CULTURALES}

\subsection{Fuentes de aprovisionamiento de materia prima}

El conjunto de datos arqueométricos obtenidos indica que la mayoría de los materiales cerámicos muestreados se elaboraron a partir de sedimentos arcillosos illítico-esmectíticos, que contenían abundantes inclusiones con una gradación de tamaños desde unos pocos micrómetros hasta aproximadamente 2,5-3,0 mm. Se identificó un sedimento con menor densidad y tamaño de grano (hasta $0,7 \mathrm{~mm}$ ) en cuatro muestras de grandes recipientes. La composición mineralógica de las inclusiones puede asociarse a la alteración y meteorización de un área granítica. Dicha mineralogía es geológicamente compatible con la zona geográfica en la que se localizan los yacimientos, por lo que los fragmentos cerámicos podrían considerarse de procedencia local. No obstante, la composición química de las cerámicas procedentes de Casa Montero, La Deseada, El Congosto y Pista de Motos difiere de las de Colector H05 y O’Donnell, lo que podría indicar la modificación de los lugares de aprovisionamiento local de las producciones cerámicas más antiguas y aquellas correspondientes a las fases avanzadas del Neolítico. El fragmento con almagra $n .^{\circ} 10$ de La Deseada presentó una composición mineralógica $\mathrm{y}$ geoquímica muy distinta al resto, indicando un probable origen foráneo.

\subsection{Métodos de fabricación}

La totalidad de los materiales cerámicos se cocieron por debajo de $700-750{ }^{\circ} \mathrm{C}$ con escaso control de las atmósferas de cocción, lo cual sugiere su ejecución en hoyo o estructuras no permanentes.

En relación a los acabados, en concreto a la "almagra" presente en el $21 \%$ de los fragmentos analizados, se apreciaron diferencias en su composición y espesor pero no en los métodos de aplicación y fijación a los recipientes: el pigmento se aplicó antes de la primera y única cocción. La "almagra", de unos $40 \mu \mathrm{m}$ de espesor medio, del fragmento posiblemente foráneo de La Deseada (muestra 10), se obtuvo casi exclusivamente con ocre. Ello contrasta con las "almagras" locales en las que un ocre mezclado con arcilla 
produjo un engobe de color rojo menos intenso y de menor espesor $(\sim 10 \mu \mathrm{m})$. Por lo demás, no es posible establecer ninguna diferenciación tecnológica entre cerámicas con o sin "almagra". Ambas se elaboraron con las mismas materias primas, incluidas la adición intencionada de hueso y/o chamota.

\subsection{Adición intencionada de desgrasantes}

Del total de 27 muestras de cronología neolítica, sólo tres carecen de desgrasantes añadidos deliberadamente. Proceden de O'Donnell y Pista de Motos y corresponden a la fase final del Neolítico regional. Por tanto, la persistencia en la adición de desgrasantes, con independencia de su tipo, es por sí mismo un rasgo característico del conjunto cerámico del VI al IV milenio cal AC y contrasta con otras áreas, como el nordeste de la Península Ibérica, donde los desgrasantes añadidos son minoritarios y variados (chamota y calcita) durante el Neolítico cardial, desparecen durante el epicardial y se generalizan y homogenizan en el horizonte postcardial (calcita) (Clop 2005: 300-302).

En más del $66 \%$ de las cerámicas analizadas se añadió de forma intencionada hueso machacado de hasta $1,5 \mathrm{~mm}$ de tamaño. Se trata del primer caso de la Península Ibérica en el que se documentan cerámicas con hueso añadido intencionadamente de estas cronologías y con esta posible continuidad temporal $(5400-3500 \mathrm{cal}$ AC) (6). En el contexto del Neolítico Antiguo europeo se conocen bien dos producciones que añaden este desgrasante orgánico de forma generalizada. El primero es el grupo de producciones cerámicas de La Hoguette (Jeunesse 1987), distribuidas mayoritariamente en yacimientos del Mosa-Rin y el alto valle del Ródano (noreste de Francia, Suiza y suroeste de Alemania), así como las producciones algo posteriores del grupo Limbourg (Modderman 1981). Con unas cronologías en torno al 5500-5200 cal AC, contemporáneas a las más antiguas de Madrid, las cerámicas

(6) Que tengan constancia los autores, el único fragmento publicado de la Península Ibérica con posibles desgrasantes óseos es el recuperado en Buraco da Moura de Saõ Romaõ en la cuenca alta del Mondego (Concelho de Seia, Portugal) (Jorge et al. 2005: 124). El alto contenido en fósforo de tres fragmentos neolíticos de la Cueva de los Murciélagos (Zuheros, Córdoba) (Martínez Fernández 1997: 301-302) quizás pueda relacionarse con la presencia de desgrasantes óseos, aunque no es esta la interpretación sugerida por Martínez Fernández. de La Hoguette son claramente distintas de las producidas por los primeros grupos de la Linearbandkeramik $(L B K)$. La mayor parte de los autores han vinculado estas producciones a grupos de ganaderos y cazadores-recolectores con posibles vínculos culturales con el llamado grupo cardial mediterráneo (Gronenborn 2007). El segundo caso es el recientemente publicado conjunto de cerámicas de yacimientos de Linearbandkeramik (LBK) de la zona de Cracovia correspondientes al Neolítico Antiguo, en los que también se han detectado desgrasantes óseos (Rauba-Bokowska 2009). Ya en el ámbito mediterráneo se reconocen casos aislados: en Renaghju (Córcega) un único vaso contiene fragmentos de hueso quemado (Bressy et al. 2007: 90); en la Provenza, en Petites-Bâties, junto a calcita y chamota en Baratin (Vancluse), y en los niveles inferiores del abrigo de Font-des-Pigeons (Bouches-du-Rhône) con chamota (Convertini 2010a: 19); en Languedoc, La Carrège (Aude) sus dos vasos alóctonos asocian chamota y hueso (Convertini 2010b: 110), y Gazel (Aude), yacimiento en el que el hueso aparece como único desgrasante (Binder et al. 2010: 119). Finalmente, el hueso ha sido localizado de forma extraordinaria entre las cerámicas del Neolítico antiguo del Valle del Aisne (Picardia) junto a fragmentos de Limbourg (Ilett y Constantin 2010: 240).

Los restos de fibras vegetales se detectaron únicamente en muestras procedentes de grandes recipientes de La Deseada, El Congosto y Colector H05. Ello, unido a que se elaboraron con sedimentos de textura más fina que el resto de los materiales cerámicos, sugiere una diferenciación tecnológica en función del tipo de recipiente. Las cerámicas de El Congosto se realizaron además con materias primas de distinta composición química.

Atendiendo a la posible funcionalidad de las producciones cerámicas analizadas y a sus condiciones de uso, debe apuntarse que la adición de desgrasantes no plásticos a un material plástico como la arcilla origina un compuesto cerámico con nuevas propiedades y cualidades técnicas. La incorporación de desgrasantes orgánicos como el hueso presenta ventajas en el proceso de elaboración, ya que acelera el secado y reduce el riesgo de roturas durante el mismo. Además, también resulta eficiente durante la cocción, especialmente en procesos de cocción de baja temperatura como los neolíticos, ya que la hidroxiapatita no 
sufre transformaciones estructurales o cambios de fase hasta temperaturas superiores a $850{ }^{\circ} \mathrm{C}$ (Rogers y Daniels 2002; Odriozola y Hurtado 2007). Otras ventajas de la adición de desgrasantes orgánicos son la reducción del peso, que hace más transportables los recipientes; así como la mejora de las propiedades mecánicas, que incide en una menor rotura por la mayor ligereza de las piezas. Por el contrario, los recipientes son menos resistentes a la abrasión y menos eficientes para calentar contenidos (Skibo et al. 1989: 139-140). Por tanto, la adición de hueso es una buena solución técnica para recipientes de almacenamiento $\mathrm{y} / \mathrm{o}$ transporte y desplazamiento, pero no para recipientes de cocina y de procesado de alimentos.

La cantidad de desgrasante de hueso añadido puede ser un indicador de comportamiento $y$, por consiguiente, de transmisión de una determinada forma de hacer cerámica. Este aspecto, pese a lo reducido de la muestra estudiada, puede detectarse en la distribución del desgrasante en los fragmentos cerámicos de cada yacimiento. Dicha distribución varía mucho entre yacimientos del Neolítico Antiguo (desviación estándar de 59,2 en El Congosto; de 39,7 en Casa Montero y de 19,1 en La Deseada). Esta tendencia va cambiando desde el Neolítico Medio en que la cantidad de hueso se hace más regular (desviación estándar de 13,3 en Colector H05), para desaparecer en el Neolítico Final.

Sólo en 4 fragmentos cerámicos se añadió chamota de tamaño inferior a 1,6 mm. Uno es el posible fragmento foráneo de La Deseada. Dos de Casa Montero y uno de La Deseada presentaron cinco inclusiones de chamota como máximo frente a las 23 del fragmento foráneo (Tab. 1). La adición de chamota incrementa las propiedades mecánicas del material (Rice 1987: 230) y se conoce en materiales cerámicos de muy diversa cronología y localización geográfica. Se documenta en más del $70 \%$ de los fragmentos cerámicos del Neolítico Antiguo de la cuenca de Alcoy, Valencia (McClure et al. 2006), en el nivel III de Kobaederra y 10-303 del Mirón en el norte de la Península Ibérica (Cubas 2008) o, de forma esporádica, en los conjuntos del noreste (Clop 2005). Entre otros lugares, se detecta en cerámicas cardiales francesas (Arnal et al. 1987; Convertini 2010a, 2010b; Binder et al. 2010; Manen et al. 2010); en Córcega (Convertini 2010a: 17; Paolini-Saez 2010: 96-97); en la base de la secuencia de Arene Candide (Convertini 2010a: 18), en materiales del Neolítico Antiguo del sur de la península italiana (Muntoni 2009; Muntoni et al. 2007); o excepcionalmente, en la Cultura de Starčevo (Biró et al. 2007). Es importante señalar el valor cronológico de la chamota en la serie de las cerámicas madrileñas, en concordancia con el panorama europeo.

\section{CONSIDERACIONES FINALES}

La muestra estudiada es todavía limitada pero permite detectar un conjunto de tendencias tecnológicas de carácter diacrónico. El aspecto más destacable del estudio realizado es la constatación del uso, prácticamente generalizado, de desgrasantes óseos añadidos intencionadamente en la mayor parte de los materiales cerámicos analizados. Este aspecto contrasta con el resto de las producciones cerámicas estudiadas de la Península Ibérica, incluidos los yacimientos más próximos del Neolítico Antiguo de la Meseta Norte como Ambrona o Cueva de la Vaquera (Joan Bernabeu com. pers.).

La ausencia de desgrasantes óseos en algunas de las cerámicas analizadas puede deberse bien a factores tecnológico-funcionales y/o cronológicos. La totalidad de los fragmentos de los yacimientos más antiguos sin desgrasantes óseos corresponden a producciones toscas de paredes gruesas, a menudo con desgrasantes vegetales observables de visu, clasificadas como grandes recipientes. Por ello, a partir de la observación macroscópica de las características formales y técnicas de los fragmentos cerámicos podría predecirse, con bastante certeza, si contienen o no desgrasantes óseos. Esto sugiere que los grupos regionales del Neolítico Antiguo y Medio quizá no incorporaban el hueso en sus producciones más expeditivas, coincidiendo con lo señalado para Provenza y Cataluña (Binder et al. 2010: 123) donde los estudios realizados hasta la fecha indican la ausencia de desgrasantes en la arcilla de los recipientes de almacenaje.

La realidad arqueológica no permite asegurar si las cualidades aportadas por los desgrasantes orgánicos se conocieron y aprovecharon desde el comienzo de las producciones cerámicas. El uso de desgrasantes orgánicos, y concretamente de hueso, tiene un carácter local generalizado y mucha variabilidad entre las vasijas con independencia de su morfología. Se trata de cerámicas 
elaboradas con materia prima local siguiendo secuencias de producción muy homogéneas, en las que la mayor diferencia reside en la cantidad de desgrasantes añadidos, no en el tipo de desgrasantes que se añaden. Por tanto, aunque se confirmase el carácter funcional inicial en la elección de hueso como desgrasante, su perpetuación en el tiempo previsiblemente resultó en un procedimiento aprendido, es decir, "socialmente determinado" (Vanmontfort 2005-2006: 102).

El único fragmento, con decoración de boquique y desgrasante óseo, entre los 5 analizados procedentes de los dos yacimientos encuadrables en el IV milenio AC, sugiere una tendencia hacia la desaparición de esta tradición tecnológica con anterioridad al Calcolítico regional. Refuerzan esta hipótesis la ausencia de hueso en los escasos estudios arqueométricos realizados a partir de cerámicas campaniformes madrileñas (p. ej., Millán y Arribas 1994) y la muestra 1 de Casa Montero, única cerámica de la Edad del Bronce aquí analizada, decorada con cordones ungulados y que tampoco presentó desgrasante óseo. Procesos similares al observado en Madrid se vislumbran en otros conjuntos neolíticos europeos, donde los rasgos distintivos de las producciones locales se atenúan a lo largo del Neolítico hasta desaparecer en el Calcolítico (7).

Destacamos en La Deseada un único fragmento con "almagra" cuya composición, ausencia de hueso y abundancia de chamota indican un origen foráneo desconocido. En cualquier caso, los materiales cerámicos no locales en la totalidad de los conjuntos analizados son siempre escasos. Si este patrón reflejase de alguna forma la realidad pretérita se podría sugerir que, aun manteniendo redes de ámbito extra-regional de carácter puntual, los grupos del Neolítico Antiguo madrileño contaban con conocimientos tecnológicos y capacidades técnicas para producir cerámica sin depender del intercambio para su propia reproducción.

Los datos obtenidos en el estudio arqueométrico sugieren que la producción de materiales cerámicos con desgrasante óseo añadido intencionadamente aparece como un fenómeno regional

(7) Vörs: Starčevo/ Lengyel III - Kostolac - Kisapostag, constatan una desaparición de desgrasantes vegetales y su sustitución por chamota que perdura hasta la Edad del Bronce (Biró et al. 2007: 26-29); o la continuidad en el uso de desgrasante óseo en las cerámicas de Hoguette-Limbourg / Bliquy-Villeneuve-Saint Germain / Cerny y su posterior desaparición (Constantin 2006: 97-98). al menos desde c. 5300 cal AC. Esta tradición tecnológica parece pervivir en la región de Madrid hasta desaparecer progresivamente en el IV milenio AC. En su segunda mitad conviven producciones de filiación formal antigua (incisas, impresas, boquique) con formas claramente asociables a conjuntos cerámicos del III milenio AC, como una fuente ovalada o sub-rectangular similar a la documentada en la fase calcolítica del yacimiento de El Espinillo (Baquedano et al. 2000: 95). Obviamente, esta tendencia se sustenta sobre una población muestral muy reducida y debe tenerse como una hipótesis de trabajo más que como conclusión.

Parece razonable considerar que la tradición tecnológica del Neolítico de la región de Madrid se vincule a grupos con movilidad residencial y baja densidad de población, como de hecho sugiere el todavía escaso registro arqueológico conocido. Es posible que las características técnicas del conjunto estuviesen encaminadas a optimizar y adecuar los recipientes cerámicos a hábitos móviles o semisedentarios (Eerkens 2008), aunque estas mejoras en el uso podrían también relacionarse con las propias ventajas de fabricación (Skibo et al. 1989: 141). En todo caso, sugieren cierta propensión al reciclaje y a la apropiación de materiales previamente utilizados para otros fines (Constantin 2006: 100; Constantin y Kuijper 2002: 779). Tanto la adición de desgrasantes orgánicos, como el espesor relativo de las paredes son ventajas en la secuencia de producción, que reducen el tiempo de elaboración y mejoran la eficacia de los materiales. Estos aspectos de la secuencia acortarían las estancias en lugares concretos durante la estación seca del año, posiblemente aquellos cercanos a sitios de aprovisionamiento de materias primas, agua y combustible para las cocciones. Otros rasgos del conjunto como la inexistencia de decoraciones profusas o la relativa sencillez de las formas sugieren también un tiempo breve dedicado a la alfarería y destinos concretos para las vasijas. Por otro lado, la mejora de las propiedades mecánicas y de transporte debida a la reducción del peso de los recipientes, es una ventaja funcional en grupos no sedentarios, tanto para sus desplazamientos como para el almacenamiento subterráneo a medio plazo. En el curso del tiempo, estos lugares persistentes podrían reducir la movilidad de los grupos e incrementar su territorialidad (Eerkens 2008: 316). 
En definitiva, los resultados aquí presentados apuntan a día de hoy, a la presencia de una tradición regional original en la Península Ibérica con cierta persistencia en el tiempo, que refuerza el panorama de regionalización de las tradiciones tecnológicas observadas en otros procesos productivos desde el primer Neolítico peninsular. Esta diversidad sugiere cambios relativamente rápidos, quizá generacionales, en la aceptación y modificación de las tecnologías aprendidas por los distintos grupos. Su posible continuidad temporal apunta a un considerable componente cultural en esta tradición regional.

\section{AGRADECIMIENTOS}

Trabajo incluido en el "Proyecto de Investigación Arqueológica en el yacimiento de Casa Montero (Madrid). Producción y circulación de sílex en el neolítico de la Meseta", financiado por Autopista Madrid Sur C.E.S.A. en el marco del convenio de colaboración entre la Consejería de Cultura y Deportes de la Comunidad de Madrid, el Consejo Superior de Investigaciones Científicas (CSIC) y Autopista Madrid Sur Concesionaria Española S.A. para la investigación, conservación y difusión del yacimiento arqueológico de Casa Montero (Madrid); Programa Consolider Ingenio 2010, Ministerio de Ciencia e Innovación, ref. TCP CSD2007-00058; y HAR2009-14360-C03-02 "Análisis comparativo de las dinámicas socioeconómicas en la Prehistoria Reciente Peninsular (VI-II milenios AC): La Meseta Sur".

Agradecemos la colaboración de Inmaculada Rus (Dirección General de Patrimonio Histórico de la Comunidad de Madrid) y del Museo Arqueológico Regional en las personas de su director, Enrique Baquedano, del conservador de colecciones Antonio Dávila y de Miguel Contreras. Antonio Uriarte elaboró la figura 1.

\section{BIBLIOGRAFÍA}

Arnal, G. B.; Gril, C. y Lalanne, J. F. 1987: “Caractérisation des céramiques préhistoriques par l'étude du dégraissant”. Archéologie Expérimentale 2: 69-79.

Baquedano, M. I.; Blanco, J. F.; Alonso, P. y Álvarez, D. 2000: El Espinillo: un yacimiento calcolítico y de la edad del bronce en las terrazas del Manzana- res. Arqueología, Paleontología y Etnografía 8. Comunidad de Madrid. Madrid.

Baxter, M. J. 1994: Exploratory multivariate analysis in archaeology. Edinburgh University Press. Edinburgh.

Binder, D.; Clop, X.; Convertini, F.; Manen, C. y Sénépart, I. 2010: "Les productions céramiques du Néolithique ancien entre Provence et Catalogne". En Cl. Manem, D. Binder e I. Sénépart (eds.): Premières sociétés paysannes de Méditerranée occidentales. Structures des productions céramiques. Société Préhistorique Française LI. Toulouse: 115-129.

Bishop, R. L. y Neff, H. 1989: “Compositional data analysis in archaeology". En R. O. Allen (ed.): Archaeological Chemistry IV. Advances in Chemistry Series 220, The American Chemical Society. Washington D.C.: 57-86.

Biró, K. T.; Gherdán, K. y Szakmány, G. 2007: “Ceramic sequence of 7000 years: archaeometrical study of pottery finds from Vörs, Máriaasszonysziget (SW Hungary)". En S. Y. Waksman (ed.): Archaeometric and Archaeological Approaches to Ceramics. British Archaeological Reports, International Series 1691, Archaeopress. Oxford: 25-31.

Bressy, C.; Bellot-Gurlet, L.; Convertini, F.; D’Anna, A.; Guendon, J.-L.; Pelletier, D. y Tramoni, P. 2007: "Matières premières et circulation des matériaux dans le Neolithique ancient de Renaghju (Sartène, Corse-du-Sud)". En A. D’Anna, J. Cesari, L. Ogel y J. Vaquer (eds.): Corse et Sardaigne préhistoriques. Relations et échanges dans le contexte méditerranéen. Actes des congrès nationaux des sociétés historiques et scientifiques $128^{\mathrm{e}}$, Bastia 2003. Documents préhistoriques 22. Paris: 87-98.

Capel, J.; Huertas, F.; Pozzuoli, A. y Linares, J. 2006: "Red ochre decorations in Spanish Neolithic ceramics: a mineralogical and technological study". Journal of Archaeological Science 33 (8): 11571166.

Clop García, X. 2005: "Las primeras producciones cerámicas del nordeste de la Península Ibérica: estudios de caracterización". En P. Arias, R. Ontañón y C. García-Moncó (eds.): Actas del III Congreso del Neolítico en la Península Ibérica (Santander 2003): 297-303. Santander.

Constantin, C. 2006: "Exemples d'utilisations de dégraissants organiques dans la céramique du Néolithique ancien et moyen de France et de Belgique: l'os, la mousse et le pavot'. Cahier des thèmes transversaux ArScAn VII - 2005-2006. CNRS, Université Paris I, Université Paris X, Ministère de la Culture. Paris: 96-100.

Constantin, C. y Kuijper, W. J. 2002: "Utilisation de mousse comme dégraissant dans des céramiques néolithiques de France et Belgique". Bulletin de la Société Préhistorique Française 99 (4): 775-783. 
Consuegra, S.; Gallego, M. ${ }^{a}$ M. y Castañeda, N. 2004: "Minería neolítica de Casa Montero (Vicálvaro, Madrid)". Trabajos de Prehistoria 61 (2): 127-140.

Convertini, F. 2010a: "Bilan des études réalisées sur la provenance de la céramique du Néolithique ancien en Méditerranée nord-occidentale. Mise au point dún protocole analytique". En $\mathrm{Cl}$. Manem, D. Binder e I. Sénépart (eds.): Premières sociétés paysannes de Méditerranée occidentales. Structures des productions céramiques. Société Préhistorique Française LI. Toulouse: 13-27.

Convertini, F. 2010b: "Désplacements de terres ou de vases? Le cas des materiaux d'origine volcanique". En Cl. Manem, D. Binder e I. Sénépart (eds.): Premières sociétés paysannes de Méditerranée occidentales. Structures des productions céramiques. Société Préhistorique Française LI. Toulouse: 105-113.

Cubas, M. 2008: "La producción cerámica en la primera mitad del V milenio Cal BC: el caso de la región cantábrica". En M. Hernández, J. A. Soler y J. J. López (eds.): Actas del IV Congreso del Neolítico Peninsular (Alicante 2007) II: 282-289. Alicante.

Díaz-del-Río, P. y Consuegra, S. 1999: "Primeras evidencias de estructuras de habitación y almacenaje neolíticas en el entorno de la Campiña madrileña: el yacimiento de 'La Deseada' (Rivas-Vaciamadrid, Madrid)". II Congrés del Neolític a la Península Ibèrica (Valencia 1999). Saguntum Extra 2: 251-258.

Díaz-del-Río, P. y Consuegra, S. 2011: "Time for action. The chronology of mining events at Casa Montero (Madrid, Spain)". Proceedings of the $2^{\text {nd }}$ Conference of the UISPP Commission on Flint Mining in Pre- and Protohistoric Times (Madrid 2009). British Archaeological Reports, International Series, Archaeopress. Oxford.

Domínguez Alonso, R. M. y Vírseda Sanz, L. 2009: "Excavación en el yacimiento Pista de Motos (Villaverde, Madrid)". Actas de las cuartas jornadas de Patrimonio Arqueológico en la Comunidad de Madrid (Madrid 2007): 327-331. Madrid.

Eerkens, J. W. 2008: "Nomadic Potters. Relationships between ceramic technologies and mobility strategies". En H. Barnard y W. Wendrich (eds.): The Archaeology of Mobility: Old World and New World Nomadism. Cotsen Advanced Seminars 4. Cotsen Institute of Archaeology, University of California. Los Angeles: 307-326.

Fugazzola, M. A.; Pessina, A. y Tiné, V. 2002: La ceramiche impresse nel Neolitico Antico. Italia e Mediterraneo. Istituto Poligrafico e Zecca Dello Strato. Roma.

García-Heras, M. y Rincón, J. M. 1996: "Microstructural and microanalytical study (SEM/EDX) of Celtiberian potsherds from the Spanish Central
Meseta". Geoarchaeology: an International Journal 11 (4): 329-344.

Gronenborn, D. 2007: "Beyond the models: 'Neolithisation' in Central Europe". En A. Whittle y V. Cummings (eds.): Going Over. The Mesolithic-Neolithic Transition in North-West Europe. Proceedings of the British Academy 144: 73-98.

Ilett, M. y Constantin, C. 2010: "La production céramique du Rubané de la vallée de l'Aisne: état des lieux". En Cl. Manem, D. Binder e I. Sénépart (eds.): Premières sociétés paysannes de Méditerranée occidentales. Structures des productions céramiques. Société Préhistorique Française LI. Toulouse: 241-248.

Jeunesse, C. 1987: “La cerámique de La Hoguete. Un nouvel 'élément non-urbanne' du Néolithique Ancien de l'Europe du Nord-Ouest'. Cahiers Alsaciens d'Archéologie, d'Art et d'Histoire 30: 5-33.

Jorge, A.; Day, P. M.; Valera, A. C.; Dias, M. I. y Prudêncio, M. I. 2005: "Ceramics, style and exchange in the Early Neolithic Upper Mondego Basin: a technological approach". En M. I. Prudêncio, M. I. Dias y J. C. Waerenborgh (eds.): Understanding people through their pottery. Proceedings of the $7^{\text {th }}$ European Meeting on Ancient ceramics (EMAC'03) (Budapest 2007). Trabalhos de Arqueologia 42: 121-128.

Linares, J.; Huertas, F. y Capel, J. 1983: "La arcilla como material cerámico. Características y comportamiento". Cuadernos de Prehistoria de la Universidad de Granada 8: 479-490.

Maggetti, M. 1982: "Phase analysis and its significance for technology and origin". En J. S. Olin y A. D. Franklin (eds.): Archaeological Ceramics. Smithsonian Institution Press, Washington D.C.: 121133.

Manem, C.; Sénépart, I. y Binder, D. 2010. “Les productions céramiques des groupes cardiaux et épicardiaux du Sud de la France: zoom regional". En Cl. Manem, D. Binder e I. Sénépart (eds.): Premières sociétés paysannes de Méditerranée occidentales. Structures des productions céramiques. Société Préhistorique Française LI. Toulouse: 191-196.

Martín Bañón, A. 2007: "Yacimiento de El Congosto (Rivas-Vaciamadrid). La fase neolítica”. Actas de las segundas jornadas de Patrimonio Arqueológico en la Comunidad de Madrid: 201-205. Madrid.

Martínez Fernández, M. J. 1997: Cerámicas neolíticas de la "Cueva de los Murciélagos" de Zuheros (Córdoba). Una contribución a la caracterización de cerámicas prehistóricas. Memoria de Licenciatura. Publicaciones en microficha. Universidad de Córdoba. Córdoba.

McClure, S. B.; Bernabéu, J.; García, O.; Aura, E.; Molina, L.; Descantes, C.; Speakman, R. J. y Glascock, M. D. 2006: "Testing technological practices: Neutron Activation Analysis of Neolithic ceramics 
from Valencia, Spain". Journal of Archaeological Science 33 (5): 671-680.

Millán, M. A. y Arribas, J. G. 1994: "La cerámica. Segunda parte: estudio tecnológico". En M. C. Blasco (ed.): El horizonte campaniforme de la región de Madrid en el centenario de Ciempozuelos. Patrimonio Arqueológico del Bajo Manzanares 2, Universidad Autónoma de Madrid. Madrid: 117-126.

Modderman, P. J. R. 1981: "Ceramique du Limbourg: Rhenanie-Westphalie, Pays Bas, Hesbaye". Helenium 21: 140-160.

Muntoni, I. M. 2009: "Early Neolithic ceramics in Southern Italy: relationships between pottery technology and production organization". En D. Gheorghiu (ed.): Early Farmers, Late Foragers, and Ceramics Traditions: On the Beginning of Pottery in the Near East and Europe. Cambridge Scholars Publishing. Cambridge: 87-115.

Muntoni, I. M.; Acquafredda, P. y Laviano, R. 2007: "Early and Middle/Late Neolithic pottery production in Northern Calabria (Italy): raw material provenance, paste preparation and firing techniques". En S. Y. Waksman (ed.): Archaeometric and Archaeological Approaches to Ceramics. British Archaeological Reports, International Series 1691, Archaeopress. Oxford: 41-48.

Odriozola, C. P. y Hurtado, V. M. 2007: "The manufacturing process of $3 \mathrm{rd}$ millennium $\mathrm{BC}$ bone based incrusted pottery decoration from the Middle Guadiana river basin (Badajoz, Spain)". Journal of Archaeological Science 34 (11): 1794-1803.

Paolini-Saez, H. 2010. "Les productions céramiques du Néolithique ancien tyrrhénien”. En Cl. Manem, D. Binder e I. Sénépart (eds.): Premières sociétés paysannes de Méditerranée occidentales. Structures des productions céramiques. Société Préhistorique Française LI. Toulouse: 89-104.

Rauba-Bukowska, A. 2009: "Bone temper in early Neolithic vessels from southern Poland. Examinations using Scanning Microscopy". En D. Hoffmann y P. Bickle (eds.): Creating Communities. New Advances in Central European Neolithic Research. Oxbow Books. Oxford: 235-248.

Rice, P. M. 1987: Pottery analysis: a sourcebook. University of Chicago Press. Chicago.

Riley, M. C. 1953: "A new roundness scale for sedimentary particles". Journal of Sedimentary Petro$\log$ 11: 94-97.

Rogers, K. D. y Daniels, P. 2002: “An X-ray diffraction study of the effects of heat treatment on bone mineral microstructure". Biomaterials 23: 2577-2585.

Skibo, J. M.; Schiffer, M. B. y Reid, K. C. 1989: "Organic-tempered pottery: an experimental study". American Antiquity 54 (1): 122-146.

Vanmontfort, B. 2006: "Considérations fonctionnelles sur le choix des dégraissnats organiques à Spiere-De Hel (Bassin de l'Escaut)". Cahier des thèmes transversaux ArScAn (vol. VII) 2005-2006. CNRS, Université Paris I, Université Paris X, Ministère de la Culture. Paris: 101-104.

Zapata, L.; Peña-Chocarro, L.; Pérez Jordá, G. y Stika, H. P. 2005: "Difusión de la agricultura en la Península Ibérica". En P. Arias, R. Ontañón y C. García-Moncó (eds.): Actas del III Congreso del Neolítico en la Península Ibérica (Santander 2003): 103-113. Santander. 